\section{Los procesos constructivos de la arquitectura clásica. De la proyección a la ejecución. El caso del Concilium Provinciae Hispaniae Citerioris de Tarraco}

\section{Building processes in Classical architecture. From projection to implementation. The case of the Concilium Provinciae Hispaniae Citerioris of Tarraco}

Josep M. Puche Fontanilles*

Institut Català d'Arqueologia Clàssica

\section{Resumen}

Toda obra arquitectónica necesita de una proyección previa que implique la definición y justificación de sus formas y proporciones, proyección que, a menudo, viene modificada por la realidad ya existente $o$, en casos de periodos constructivos largos por cambios de opinión, de finalidad o, incluso de promotor. Es el caso del Concilium Provinciae Hispaniae Citerioris de Tarraco, un gran complejo monumental de más de 12 hectáreas de extensión, que necesitó un periodo de tiempo de construcción de entre 70 a 75 años. Los restos arqueológicos conservados permiten la identificación de dos proyectos arquitectónicos sobrepuestos que implican un profundo cambio de proyecto durante el proceso constructivo.

Palabras clave: Tarraconense, modulación, proyecto arquitectónico.

\begin{abstract}
Any architectural work requires a previous projection involving the definition and justification of its forms and proportions. This projection is often modified by an existing reality or, in cases of long constructive periods, by changes of opinion, aim or, even, promoter.

This is the case of the Concilium Provinciae Hispaniae Citerioris, a monumental complex, more than 12 hectares large, which was likely built in 70-75 years. The archaeological remains allow identifying two successive architectural projects which involve a major change while the building is in progress.
\end{abstract}

Keywords: Tarraconense, modulation, building project.
Hay una arqueología de la arquitectura, entendida como la lectura y estudio con metodología arqueológica de la arquitectura. Pero también hay una arquitectura de la arqueología, el estudio arquitectónico de los restos arqueológicos, cuyo objetivo final no es otro que entender y explicar (tanto diacrónica como sincrónicamente) un edificio o monumento a partir de los restos que de él se han conservado.

Es obvio que, dentro de esta perspectiva, se puede afrontar el estudio arquitectónico de restos arqueológicos desde varios enfoques diferentes y necesarios en tanto y en cuanto se centran en algún aspecto parcial de una totalidad. Estos serían el estilístico, el técnico, el historicista, el funcional y el formal.

Estilístico: Estudia como son los restos, sus elementos decorativos y su disposición. Intenta encuadrarlo dentro de grupos taxonómicos y ver posibles influencias o variaciones del patrón teórico original. Es un tipo de enfoque muy vinculado a la historia del arte e historiográficamente quizás el más habitual.

Técnico: Estudia cómo está hecho, qué técnicas constructivas se han utilizado. Analiza, si se puede, el juego de solicitudes de esfuerzos, tanto los originales como los sobrevenidos a lo largo del tiempo, así como las soluciones técnicas que se han aplicado. Sus lesiones, colapsos, etc.

Historicista: Lo encuadra cronológicamente e intenta explicar sus vicisitudes. Hace el análisis diacrónico y evolutivo de los restos. El momento de su construcción, los cambios sufridos, su periodo de vida, su propiedad, etc... Es, quizás, el enfoque tradicionalmente más utilizado en arqueología.

Funcional: Aquí se intenta explicar su uso, las funcionalidades que ha tenido, por qué se construyó, como se utilizó este edificio y los usos y usuras que ha tenido a lo largo de su vida.

Formal: Analiza la forma cómo nos ha llegado el edificio. Cuál era su forma original, o cual era la forma que se deseaba, qué variaciones ha sufrido y, sobre todo, porqué su forma es la que es y no es otra.

Es una obviedad apuntar que todas estas lecturas están fuertemente interrelacionadas unas con las otras y que sólo un estudio que los trate conjuntamente se podría considerar un estudio completo. En este artículo no se pretende hacer un estudio global de unos restos arquitectónicos determinados (esto trascendería la finalidad y la capacidad de un simple artículo), sino profundizar en uno de estos enfoques particulares, uno de los aspectos, quizás, tradicionalmente menos estudiados, pero que puede aportar información muy significativa y trascendental: el estudio de la 
forma. Afrontar un monumento determinado desde la forma en que se pensó hasta la que nosotros conocemos.

\section{LA IMPORTANCIA DE LA FORMA}

Se podría definir la arquitectura como la habilidad de ocupar y organizar el espacio ${ }^{1}$. Este espacio se organiza mediante el uso y la combinación de diferentes formas, que se materializan a partir del uso (o de la ausencia) de los elementos constructivos (muros, cubiertas, espacios abiertos, etc...). Con respecto a la forma final de un edificio, esta se consigue básicamente con el uso múltiple de un determinado número de formas simples (normalmente pocas) y de las interrelaciones que entre ellas se establecen². O dicho de otra manera, la forma final de un edificio se establece a partir del dimensionado de unas formas generatrices y de las proporciones que se establecen entre ellas. Y mencionamos el término proporción, puesto que este y la forma están completamente vinculados y no tienen sentido uno sin el otro (Scholfield 1971).

Para entender la importancia de la forma dentro de la arquitectura (y por lo tanto lo importante que es comprender la forma para comprender la arquitectura) se ha de entender el proceso constructivo, sobretodo el momento de la idealización y proyección del edificio. Se debe tener presente, principalmente, que la arquitectura no es sólo funcional; la arquitectura también sirve (a veces fundamentalmente) como medio de expresión ideológica, como una creación con un fuerte componente semántico.

Un edificio, un monumento, es mucho más que un objeto físico fabricado por el hombre. Es la materialización de una voluntad y de una capacidad determinada. Todo edificio nace a partir de una decisión o de una necesidad. Alguien quiere, o necesita, conseguir unos objetivos concretos y para hacerlo ha de organizar un espacio de una forma determinada.

Y lo hará de una manera específica, condicionado, en primera instancia, por esa misma voluntad que dictará la forma. No tendrá la misma forma una estructura destinada a defender un área determinada, que otra que debe permitir conservar alimentos o de aquella destinada a

\footnotetext{
${ }^{1}$ Hacemos nuestra la siguiente cita de Gilles Ivain «La arquitectura es la forma más simple de articular el espacio y el tiempo, de modular la realidad, de hacer soñar. No es sólo una articulación y una modulación plástica, expresión de una belleza pasajera, sino también una modulación influencial que se inscribe dentro la curva eterna de los deseos humanos y de los progresos en la materialización de dichos deseos» (Ivain 1958).

2 «La arquitectura es arte en su sentido más elevado, es orden matemático, es teoría pura, armonía completa gracias a la exacto proporción de todas las relaciones: Esta, y no una otra, es la función de la Arquitectura» (Corbusier 1923).
}

baños. O de una con objetivos funerarios. No en vano a partir de la forma es fácil deducir el tipo y la función de un edificio.

Con posterioridad, se sitúa la capacidad (técnica, económica, organizativa) de poder materializar esta voluntad y todos aquellos factores externos que pueden interferir en el proceso (cambios en la voluntad o en la capacidad, la usura del tiempo, los factores históricos...). La conjugación de todos estos elementos serán los que, en última instancia, darán la forma final en la que nos ha de llegar ese edificio.

Decíamos que primero hay una voluntad, la cual está profundamente condicionada por el entorno cultural y social en el que se sitúa. Las concepciones y percepciones religiosas, de interrelación social, la forma de entender el espacio, los usos y hábitos, la propia psicología personal, y un largo etc. determinarán de qué manera se materializa esta voluntad. Y esta, para poder hacerse realidad, necesita de una planificación, que puede estar más o menos verbalizada.

Es cierto que la forma de un edificio está destinada a cubrir las necesidades para la cual se ha construido, pero no es menos cierto, que los condicionantes ideológicos sociales y culturales pueden influir tanto o más que los factores de tipo práctico.

Se podría decir, que para lograr un objetivo determinado, hay múltiples posibilidades formales. $\mathrm{Y}$ es en la selección de una u otra de estas posibilidades dónde intervienen de manera muy intensa estos condicionantes; el cómo se entiende y cómo se percibe el concepto (y la funcionalidad social) del edificio arquitectónico.

Evidentemente, cuánta más carga simbólica y representativa tenga un edificio, más peso tendrán los condicionantes ideológicos ${ }^{3}$. Podemos decir, pues y sin miedo a exagerar, que la idiosincrasia y el bagaje cultural-filosófico determina, en numerosos casos, de manera fundamental la forma de la arquitectura. O, como decía Van der Rohe (1924), la «arquitectura es la voluntad de la época traducida a espacio».

En consecuencia, si los parámetros ideológico-culturales intervienen de forma decisiva en la forma de un edificio, se puede deducir que a partir del análisis de la

\footnotetext{
3 Tenemos un ejemplo muy ilustrativo con la forma de la mayor parte de las iglesias cristianas que presentan una planta en forma de cruz. Aquí la forma viene definida, casi en exclusiva, por la utilización de un determinado símbolo con fuertes connotaciones religiosas. Lo mismo sucede con los baptisterios octogonales, en los cuales su forma (de ocho lados) viene definida por concepciones mágico-religiosas. Estos son dos ejemplos de cómo los aspectos simbólicos determinan la forma del edificio (López y Puche, en prensa).
} 
forma de un edificio se puede ser capaz, teóricamente, de ver y entender los conceptos ideológico-culturales de sus constructores. Como se entendió y como se concibió ese espacio determinado.

Y para entenderlo tenemos que pasar, obligatoriamente, por el concepto de proyección.

Ya hemos señalado que toda construcción (no sólo arquitectónica), por su propia naturaleza, implica necesariamente una proyección previa, una visualización de cómo ha de ser y de cómo han de ir distribuidas sus partes. Es obvio que cuanto mayor y más compleja sea, más clara y evidente habrá de ser su proyección; para hacer una mesa o un chamizo, sólo hará falta una visualización interna, tener claro mentalmente cómo debería ser y cómo situar y colocar los elementos que lo configuran. Por el contrario, si lo que se quiere construir es una gran domus, o un edificio público monumental, aquí la proyección tendrá que ser mucho más explícita, compleja y capaz de resolver verbalmente todas las interrogantes que se planteen (Taylor 2003, 36-37).

Y a la hora de verbalizar la proyección de un elemento, es especialmente importante definir la forma y cómo esta se organiza; cómo se distribuyen las diferentes medidas (alzado, longitud, ancho) y volúmenes y cómo se relacionan entre sí. Estamos hablando, simplemente, de proporción y de modulación.

Es obvio que estos no son los únicos elementos que intervienen a la hora de definir la forma y dimensiones de un edificio; la utilidad, la estabilidad estructural, los factores económicos y las limitaciones técnicas del momento, son otros determinantes a la hora de definir la forma de una construcción. Estos elementos, una vez establecidos, pueden ofrecer, tal y como ya se ha apuntado anteriormente, una gran cantidad de posibles soluciones. $Y$ es la proporción (o mejor dicho la teoría de la proporción que se aplique en ese momento) quien determinará cuál de las numerosas opciones posibles es la más conveniente y adecuada.

Se debe tener presente que, en contra de una opinión muy generalizada, la proporción no tiene una única finalidad estética, sino que está íntimamente ligada a la economía de proyección y construcción. El hecho de establecer un modelo coherente de formas y medidas facilita enormemente los trabajos de proyección y, sobre todo, los de construcción. No olvidemos que en una edificación interviene un gran número de personas y a menudo de campos profesionales muy diferentes (albañiles, canteros, carpinteros, herreros, etc). Trabajar con un sistema en el que las medidas de los elementos mantienen una coherencia y proporción interna facilita enormemente la conjunción de trabajos tan dispares.

No obstante, es cierto que, pese a esta indudable utilidad, en la proporción también interviene, y no de forma marginal, la cuestión estética. La distribución de formas dentro del espacio no siempre resulta agradable a la percepción humana y, por lo tanto, es de esperar que haya una tendencia natural a buscar y crear combinaciones de formas agradables, estéticas. Aunque no sea un axioma universal, es evidente que unas determinadas proporciones son más agradables a la vista que otras. No siempre y no para todo el mundo, pero es indiscutible que ciertas combinaciones de dimensiones tienen una mayor aceptación (Scholfield 1971, 21 y Livio 2006, 199)4. Y esta es la razón por la cual algunas de ellas son, estadísticamente, más repetidas que otras, con independencia del marco cultural y cronológico 5 .

La principal razón de este fenómeno no estriba únicamente en una causa genético-psicológica, sino que hay motivaciones de carácter matemático y geométrico. Precisamente las proporciones más habituales son aquellas que presentan una serie de propiedades matemáticas y geométricas peculiares y, a menudo, únicas. Propiedades que permiten la construcción, de manera simple, rápida e intuitiva, de formas complejas a partir de formas simples.

Cuando hablamos de proporciones, hablamos, evidentemente, de simetría y módulo. ¿Qué se entiende exactamente por simetría y cómo se define módulo? Este sería un tema largo a desarrollar y que se merecería un tratamiento extenso y profundizado, sobre todo si se considera que son dos términos que tienen significados matizados en cada periodo histórico. No obstante, y siendo consciente del riesgo que corremos al simplificar (y banalizar) su explicación, se puede decir que la simetría es la relación ordenada y coherente entre dos o más formas o medidas y el módulo la forma básica que, repetida, configura la forma general. Evidentemente, son dos términos íntimamente interrelacionados; el módulo necesita la simetría para poder configurar elementos superiores, de la misma manera que la simetría hace uso del módulo para establecer las relaciones entre las partes. Para poder entender esta interrelación, se tiene que tener muy claro un concepto básico: en arquitectura, el resultado de la proyección (es decir el edificio), para que sea útil (y

\footnotetext{
${ }^{4} \mathrm{Al}$ respecto, consultar los interesantes experimentos de G.T. Fechner en la década de los 60 del siglo XIX o los estudios más actualizados de McManus de 1980, o Stone-Collins en 1965 (Livio 2006, 202-203).

${ }^{5}$ Esta afirmación es una generalidad. Sirve para indicar una tendencia generalista, no un axioma universal.
} 


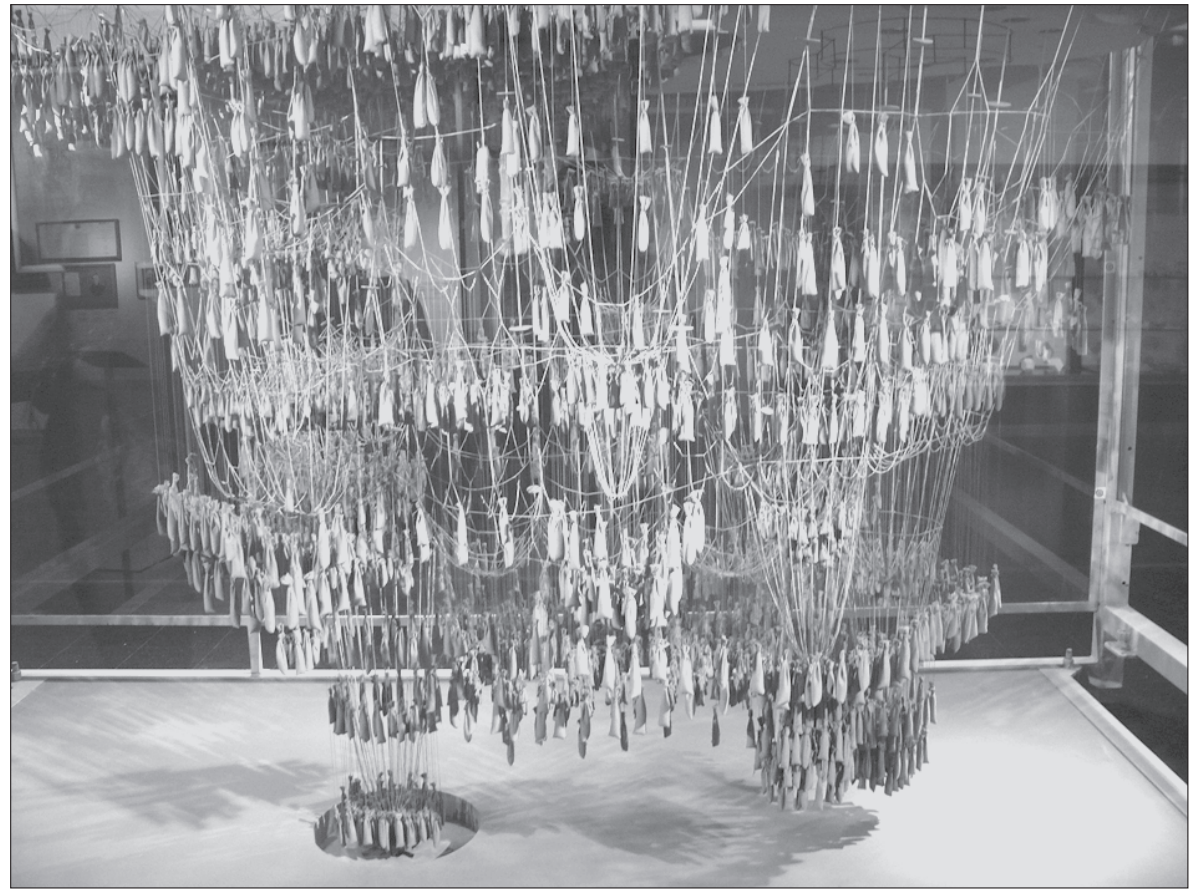

Fig. 1. Maqueta funicular de la Sagrada Familia de Gaudí. La proyección arquitectónica a partir de la geometría estético $^{6}$ ), debe ser un complejo armónico y ordenado, y esto se puede conseguir, básicamente, con el uso repetitivo y coherente de formas básicas.

La repetición ordenada de formas simples crea un sistema fácil de proyectar $y$, obviamente, fácil de construir. Pudiéndose legar a eliminar la necesidad de cálculo.

Se ha de recordar que, históricamente, tanto la proyección como la ejecución de una obra se han realizado a partir de la geometría, no de la aritmética. Se define el edificio a partir de cuerdas, arcos y alineaciones, tanto sobre el papel como sobre el terreno ${ }^{7}$ (Fig. 1).

A partir de la práctica y de la lógica constructiva se puede extraer una última conclusión. Los principios de efectividad, economía y simplificación dan sólo un número reducido de posibles combinaciones de formas y medidas factibles. Es decir, que entre las infinitas posibilidades constructivas que puede dar la proporción, solo un número reducido de ellas cumple con las exigencias de economía, solidez y armonía.

Sin descartar para nada el uso de otras muchas, las proporciones más habituales son, naturalmente, las más simples, las aritméticas basadas en números simples: 1/1,

\footnotetext{
${ }^{6}$ A veces la estética se interpreta como un elemento útil más. O dicho de otra forma, en ciertos periodos y ambientes culturales lo útil tiene que ser forzosamente bello, de lo contrario, no es útil (Taylor 2003, 30-35).

${ }^{7}$ Como ejemplo ilustrativo, ver los sistemas utilizados por Gaudí para calcular las formas parabólicas de sus edificios. No utilizaba el cálculo matemático, simplemente invertía maquetas hechas con cables para encontrar formas complejas pero estructuralmente estables.
}

$2 / 1,3 / 1$, etc. Pero no es nada extraño encontrar proporciones basadas en fracciones que dan números inconmensurables, $1 / \sqrt{ } 2,1 / \sqrt{ } 3, \varphi$, etc.

No nos debe sorprender el uso común de estas últimas. Su facilidad de construcción, simple e intuitiva, y el enorme juego que dan sus propiedades geométricas las hacen especialmente útiles y atrayentes.

Es cierto que algunas de estas proporciones, en determinados momentos o ámbitos culturales, han adquirido un valor semántico concreto, un valor buscado y argumentado en principios mágico-filosóficos. Pensamos, principalmente, en la llamada proporción aurea, la proporción $\varphi$, cuyo uso semántico se debe a la búsqueda de un argumento que explique la peculiaridad de sus propiedades y el porqué aparecen de forma natural, espontánea y de manera armónica, en multitud de situaciones.

\section{PROPIEDADES BÁSICAS DE LAS PROPORCIONES MÁS USUALES}

\section{Proporción 1/1 (Fig. 2)}

La proporción 1/1 es muy simple, un cuadrado dónde sus dos longitudes (largo por ancho) son idénticas. No tiene más explicación. Se podría relacionar con el círculo, pues las dos formas son básicas y tienden a enmarcar un espacio en que las dimensiones tienen un único valor. Precisamente por su simplicidad, es una forma muy dúctil y presenta una infinidad de posibilidades. 

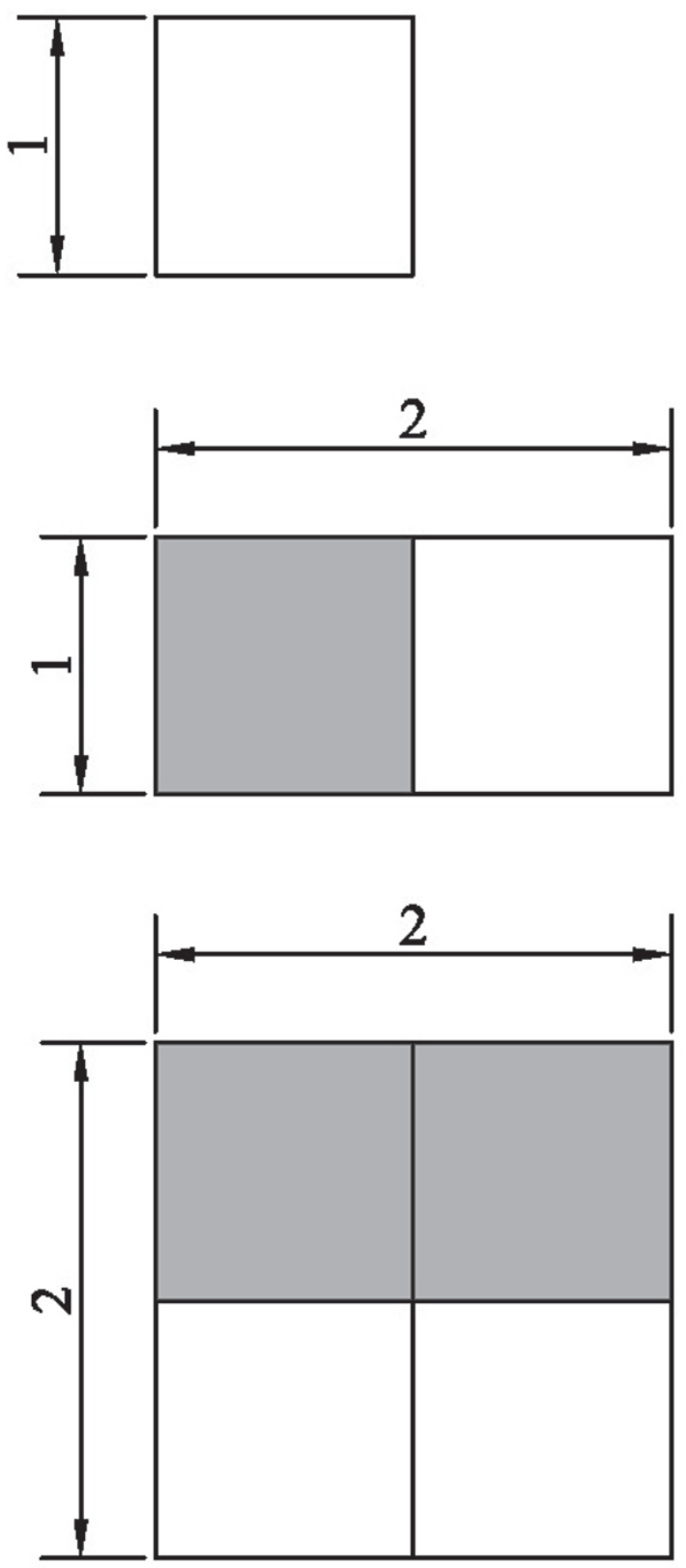

Fig. 2. Proporción $1 / 1$ y sus múltiples

Las otras proporciones simples $2 / 1,3 / 1$, etc. son simplemente una multiplicación de la anterior. Presentan la peculiaridad de ser rectángulos construidos a partir de cuadrados, pero que a la vez pueden volver a construir otros cuadrados. Dos cuadrados forman un rectángulo de proporción $2 / 1$, y dos rectángulos de estos tipos unidos por el lado largo dará otro cuadrado $2 / 2$, que será 4 veces el cuadrado original (Fig. 2).

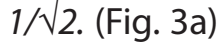

Pese a la aparente complejidad de su definición, se visualiza con un rectángulo construido a partir de un cuadra- do, en el que el lado largo tiene la misma longitud que la diagonal. Parece una proporción compleja pero, en el fondo, es de una gran simplicidad constructiva. Geométricamente hablando, ya que aritméticamente genera un número irracional (1 dividido por raíz de 2 sólo se puede representar como fracción), y como tal no tiene una solución numérica simple. Pero repetimos lo dicho anteriormente. En arquitectura, históricamente, la proyección y su cálculo se basa en la geometría. Si una forma tiene fácil solución geométrica, aunque aritméticamente sea compleja, su uso será, necesariamente, fácil y simple.

\section{Phi (Fig. 3b)}

La proporción phi $(o \varphi)$ es la llamada proporción aurea. Es aquella que matemáticamente se puede determinar con la ecuación $x^{2}=x+1$. Al igual que la anterior, parece compleja y también genera un número inconmensurable. Pero también al igual que la anterior, es de una construcción geométrica de extrema simplicidad. De un cuadrado se construye un rectángulo a partir de la diagonal que se dibuja desde el punto central de uno de sus lados hasta uno de los ángulos hallados.

Esto da una proporción en la que el lado largo dividido por el pequeño es igual que la suma de los dos lados dividido por el largo. Este hecho, tanto matemática como geométricamente, da un juego increíble de una potencialidad asombrosa. De hecho, y por esta razón, la proporción phi se encuentra en infinidades de ejemplos en la naturaleza, desde nivel molecular hasta la distribución de las nebulosas, pasando por la filotaxis (crecimiento de las hojas de los árboles) ${ }^{8}$. No es de extrañar, pues, que esta proporción haya sido siempre objeto de especial atención y se la haya considerado, en determinados momentos, bajo una óptica mágica o divina?

Se ha discutido mucho sobre su uso en época antigua (Wilson Jones, 2003; Markowsky, 1992) y se duda, incluso, que se aplicara en arquitectura antes del Renacimiento. Todavía se discute su aplicación en el mundo griego y

\footnotetext{
${ }^{8}$ Se debe recordar la estrecha relación que hay entre esta proporción y la conocida serie numérica de Fibonnaci (1-2-3-5-8-13-21-34-55...), en la que cada número es la suma de los dos anteriores. Esta serie presenta la peculiaridad de que entre un número y el consecutivo se establece una relación aurea (más cercana cuando más grande sean los números). Así, las proporciones establecidas a partir de números consecutivos de Fibonnaci se pueden considerar proporciones áureas: 5-3, 8-5, etc. Esta serie aparece definida por primera vez en el capítulo XII del Liber Abaci, de Fibonnaci.

9 La primera en atribuirle propiedades mágicas y darle un valor semántico propio, basado en conceptos filosóficos, fue la escuela pitagórica ya desde el siglo V a.C. Euclides, en su Elementos, la define y la describe matemáticamente. Sin olvidar que según Platón era la proporción que más abundaba en la naturaleza.
} 
a)

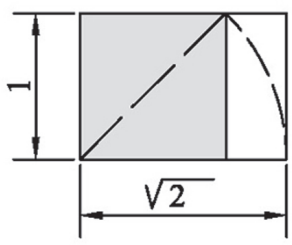

$\sqrt{2}=($ aprox.) 1,4 b)

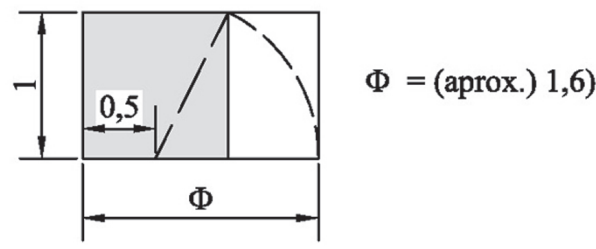

Fig. 3. Proporciones inconmensurables. Rectángulo en proporción raíz de 2 y phi
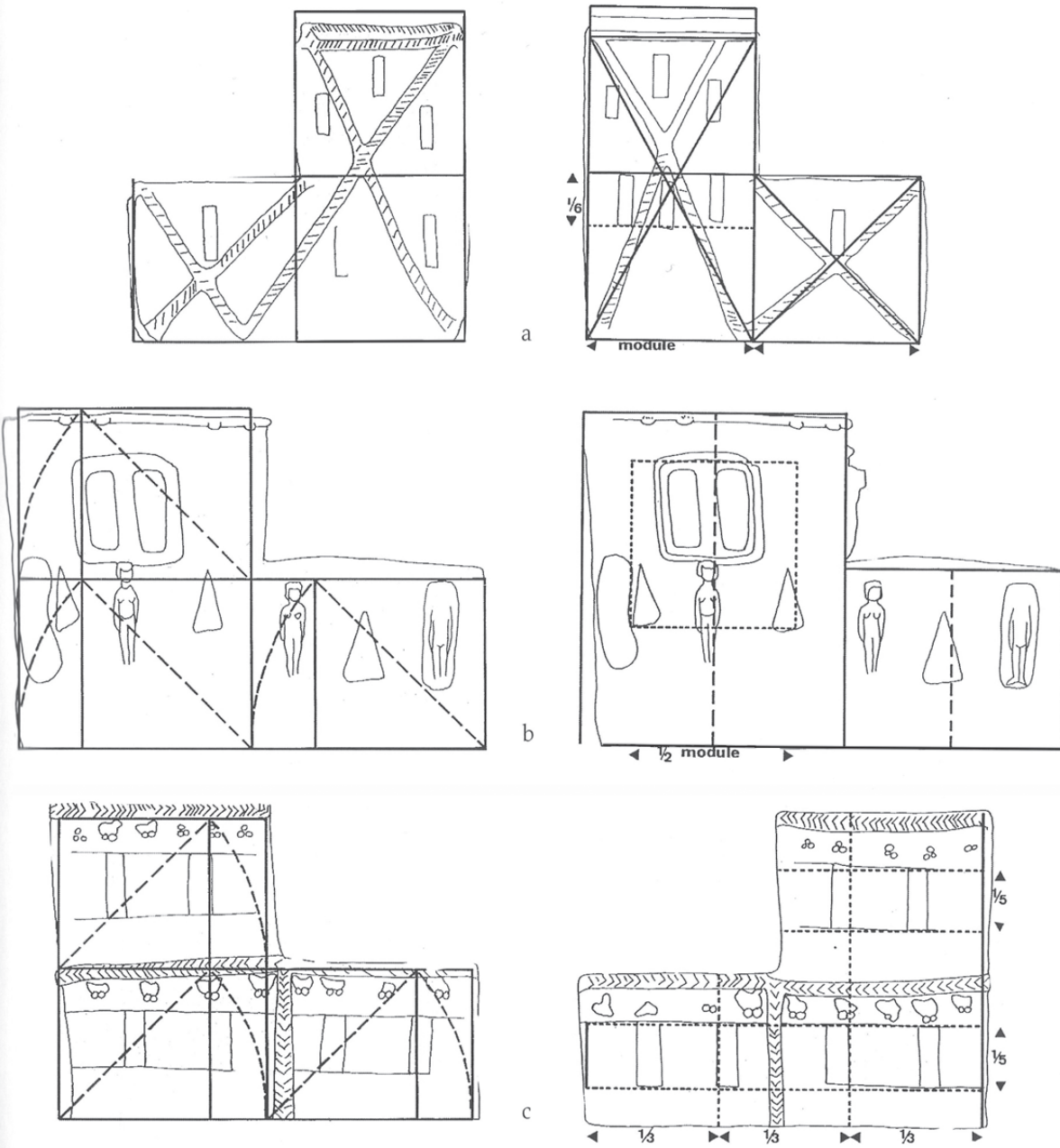

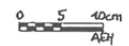

Fig. 4. Terracotas arquitectónicas del $2^{\circ}$ milenio a.C. con proporciones inconmensurables

romano, pero la verdad es que se puede documentar su uso en terracotas arquitectónicas mesopotámicas del $2^{\circ}$ milenio a.C. (Fig. 4) ${ }^{10}$ y se apunta su uso semántico desde

\footnotetext{
${ }^{10}$ La proporción de 1/»2 y la áurica presentan una construcción prácticamente idéntica y, teniendo en cuanta el conocimiento teórico de la primera por parte de los romanos (Vi, VI, iv, 18), no sería nada incongruente suponer un uso consciente de la proporción phi en la arquitectura de época clásica.
}

época paleocristiana, como mínimo (Puche 2006, Puche et alii 2007 y Lopez y Puche, en prensa).

\section{LA PROPORCIÓN EN ÉPOCA CLÁSICA}

Hasta ahora se ha intentado ver y analizar esquemáticamente cuál es el concepto de proporción así como su peso y valor dentro del hecho arquitectónico. Pero ¿qué pasa en el mundo clásico? Es obvio, por la complejidad y dimen- 
siones de sus construcciones, que hay y se aplica un concepto particular de proporción y modulación. Más difícil es intentar entender y describir cuál es ese concepto. Este sería un tema de estudio extensísimo sobre el que, quizás a veces, se ha hablado demasiado y de forma bastante frívola ${ }^{11}$, muy a menudo llegando a conclusiones completamente contradictorias.

Más que en el estudio directo de los edificios, donde se puede captar cuál podría ser la concepción que se tenía de la proporción es en las fuentes históricas, en los tratados matemáticos, geométricos, filosóficos y arquitectónicos de la época.

Tenemos un conocimiento muy precario de cómo era la concepción antigua de la proporción y de cómo esta se aplicaba, pero es indiscutible que la tenían y que eran conscientes de ella hasta el punto de poder verbalizarla. Vitrubio, el autor de la única obra clásica que nos aporta información directa del concepto de proporción en la arquitectura, es de gran ayuda, aunque totalmente insuficiente. En su obra parece dar por supuesto que el lector es conocedor de los principios teóricos de la proporción, lo que podría explicar su carencia de concreción al respeto. Lo que sí se ve claro es que Vitrubio consideraba que el conocimiento y la aplicación de los principios de la proporción eran imprescindibles en la arquitectura. No en vano, en el capítulo II del primer libro (en el capítulo I habla del oficio de arquitecto) enumera las partes en que consta la arquitectura; Ordenación, Euritmia, Simetría, Decoro, y Distribución, en este orden y define la primera de ellas, la Ordenación, como «...la apropiada comodidad de los miembros en particular del edificio, y una relación de todas sus proporciones con la simetría. Se regula por la Cantidad, que en griego se llama posotés. Y la Cantidad es una conveniente dimensión por módulos de todo el edificio y de cada uno de ellos» (Vi, I, ii, 14).

Más adelante habla de la Disposición que la define cómo «...una apta colocación y efecto elegante de la composición del edificio..." (Vi, I, ii, 15) y, cuando describe sus tipos (Icnografia, Ortografía y Scenegrafia), describe, de hecho, las formas de representar gráficamente un edificio: planta, alzado y perspectiva.

Por si hubiera alguna duda de la importancia que le da a la proyección y al papel que en ella tiene la proporción, insiste en el tema en el capítulo II del libro VI cuando dice,

\footnotetext{
${ }^{11}$ Sólo, y a modo de ilustración, se deben ver los innumerables trabajos y las conclusiones a menudo contradictorias que se han hecho sobre el Partenón. Como ejemplo reciente de un enfoque acertado de estudio geométrico de la arquitectura, a nuestro parecer, ver el interesante trabajo de Arias Páramo (2008) sobre la arquitectura prerrománica de Asturias.
}

literalmente "En nada debe poner más cura el arquitecto como que los edificios tengan en sus partes una exacta conmensuración «(Vi, VI, ii, 1). Y más adelante aclara «Establézcase, pues, en primer lugar la razón de la simetría, a la que se acordará con seguridad cualquier cambiamiento que se hiciera, y después se determinará la longitud y latitud de la planta del edificio a construins (Vi, VI, ii, 12). No queremos entrar a analizar este autor, pero es innegable la importancia que para él tiene la correcta composición y ordenación interna de un edificio. Son lo suficientemente conocidas las relaciones proporcionales que, según él, deben tener los edificios o ciertas partes de ellos; la definición de las medidas de ciertas partes de las domus o la distribución de las proporciones en los templos serían dos ejemplos paradigmáticos. En fin, que no sólo considera que una construcción debe estar bien proporcionada, sino que el tipo de proporción se debe determinar incluso antes de definir las dimensiones del edificio. En otras palabras, se define el equilibrio de las formas antes que cualquier otro factor $y$, una vez establecido este, el arquitecto ya puede empezar a considerar los otros elementos que definirán su obra ${ }^{12}$.

En ausencia de tratados teóricos solo se puede recurrir a los proyectos verbalizados para intentar ver la plasmación de ese concepto, sobre todo considerando que la arquitectura clásica nos ha llegado enormemente alterada (cuando no fragmentada). El problema es que no conocemos proyectos de época clásica, sólo conocemos representaciones gráficas (pocas) de edificios ya construidos (la forma urbis sería quizás uno de los ejemplos más paradigmático), pero se tratan de documentos realizados con una finalidad documental. No obstante, aunque no conocemos representaciones gráficas de proyectos, sí que conocemos maquetas que corresponden claramente a proyectos constructivos, siendo, quizás, el caso más evidente la maqueta en piedra del adyton del templo de Niha (cerca de Baalbek) con anotaciones hechas con carboncillo ${ }^{13}$ (Fig. 5).

Esto implica que, al fin y al cabo, la única fuente para poder acercarnos a estos conceptos es una arquitectura que nos ha llegado incompleta y profundamente alterada.

No obstante, se puede afirmar que la arquitectura romana era consciente de la necesidad de una proyección previa y de su verbalización. Igualmente, se daba extrema importancia a la distribución correcta de medidas, a la

\footnotetext{
${ }^{12}$ Remarquemos que cuando habla de la Icnografia, Ortografía y Scenegrafia, lo hace de la forma de representar gráficamente un edificio, y esta necesidad de representar sólo tiene sentido si se tiene que verbalizar la idea de cómo se quiere que sea el edificio. Es decir, a la hora de proyectar.

${ }^{13}$ No deja de ser significativo que el edificio real, que es bien conocido, difiera en detalles de la maqueta, y que precisamente los detalles diferenciales corresponden con las anotaciones hechas con carbón (Muller 1998).
} 


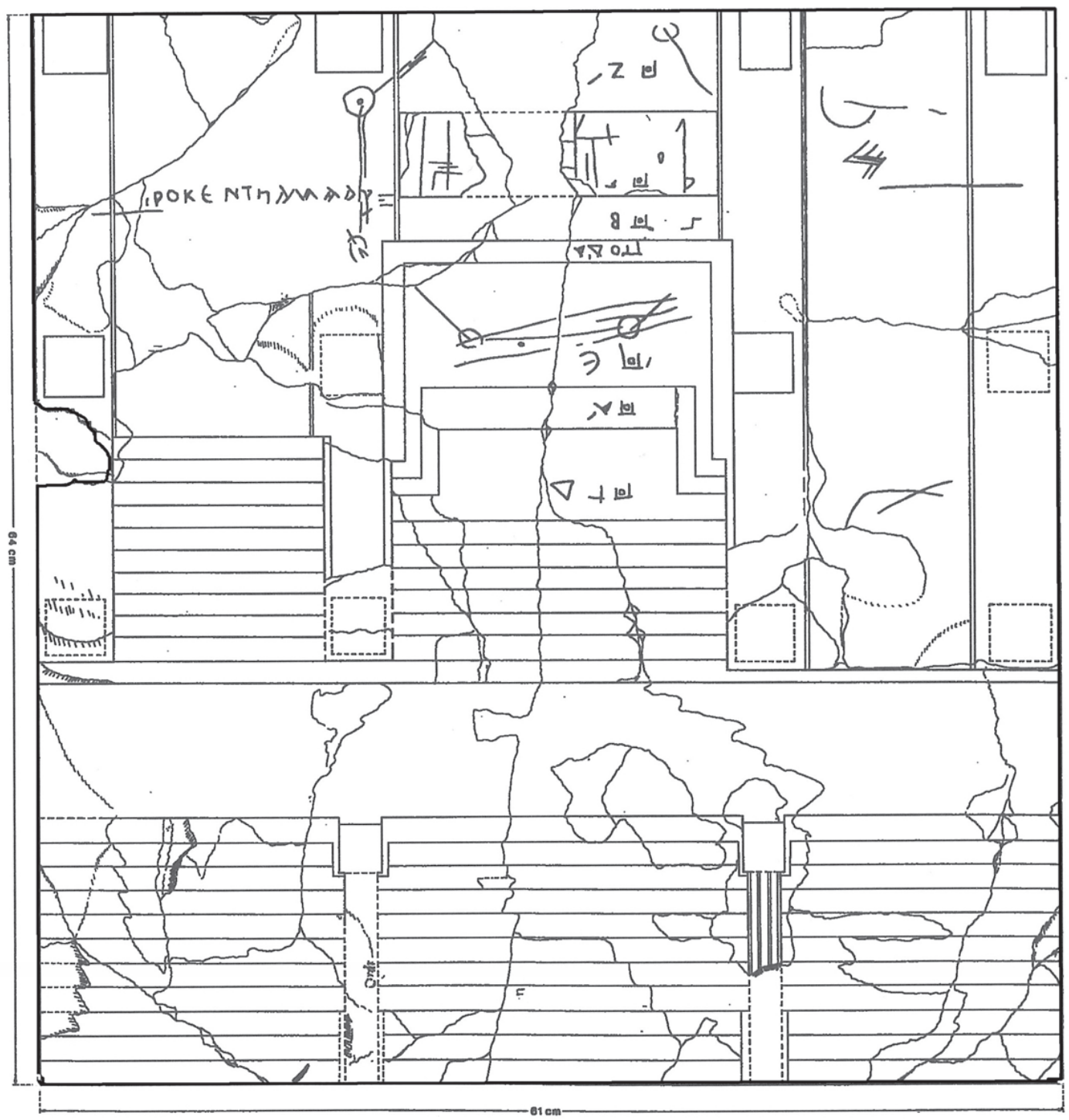

Fig. 5. Maqueta de mármol de Niha

proporción y a la ordenación de los módulos. Y esto es el que ahora nos importa, saber que en época romana hay una proyección previa a la construcción y que en esta proyección participan los conceptos geométricos de módulo y proporción (Taylor 2003, 44). No entraremos a analizar cuál era ese concepto de proporción, qué es lo que se consideraba un edificio bien proporcionado, este es otro tema que necesitaría un estudio particular ${ }^{14}$.

Lo que queremos es intentar analizar los restos que han llegado a nosotros para ver qué tipos de proporciones se utilizaron, y cuáles eran los parámetros geométricos básicos aplicados en la proyección de un edificio determinado.

14 Sólo hace falta ver la problemática del uso de determinados números irracionales (principalmente las proporciones $1 /$ raíz de 2 y phi) en la arquitectura clásica (Caveing 1998, Esposito y Michetti 1996 y Puche 2006, como ejemplo).
No es un trabajo fácil y a menudo resulta imposible: La implantación en el terreno del modelo teórico, las modificaciones en curso de obra, las remodelaciones posteriores, las destrucciones sufridas o el conocimiento parcial que se pueda tener de una construcción en concreto pueden enmascarar totalmente la proyección original de un edificio de época romana. En compensación, si en un edificio parcialmente conocido se consigue establecer el módulo y la proporción, se puede teorizar con base sólida sobre las partes ausentes, al mismo tiempo que aproximarse, no ya a la realidad del edificio o de un espacio concreto, sino a la concepción que se tenía de él.

Es necesario recordar que en la proyección, en la verbalización de lo que se quiere construir, es donde el constructor (o el promotor) imprime su idiosincrasia, su filosofía, su voluntad y su visión de cómo debería ser la 


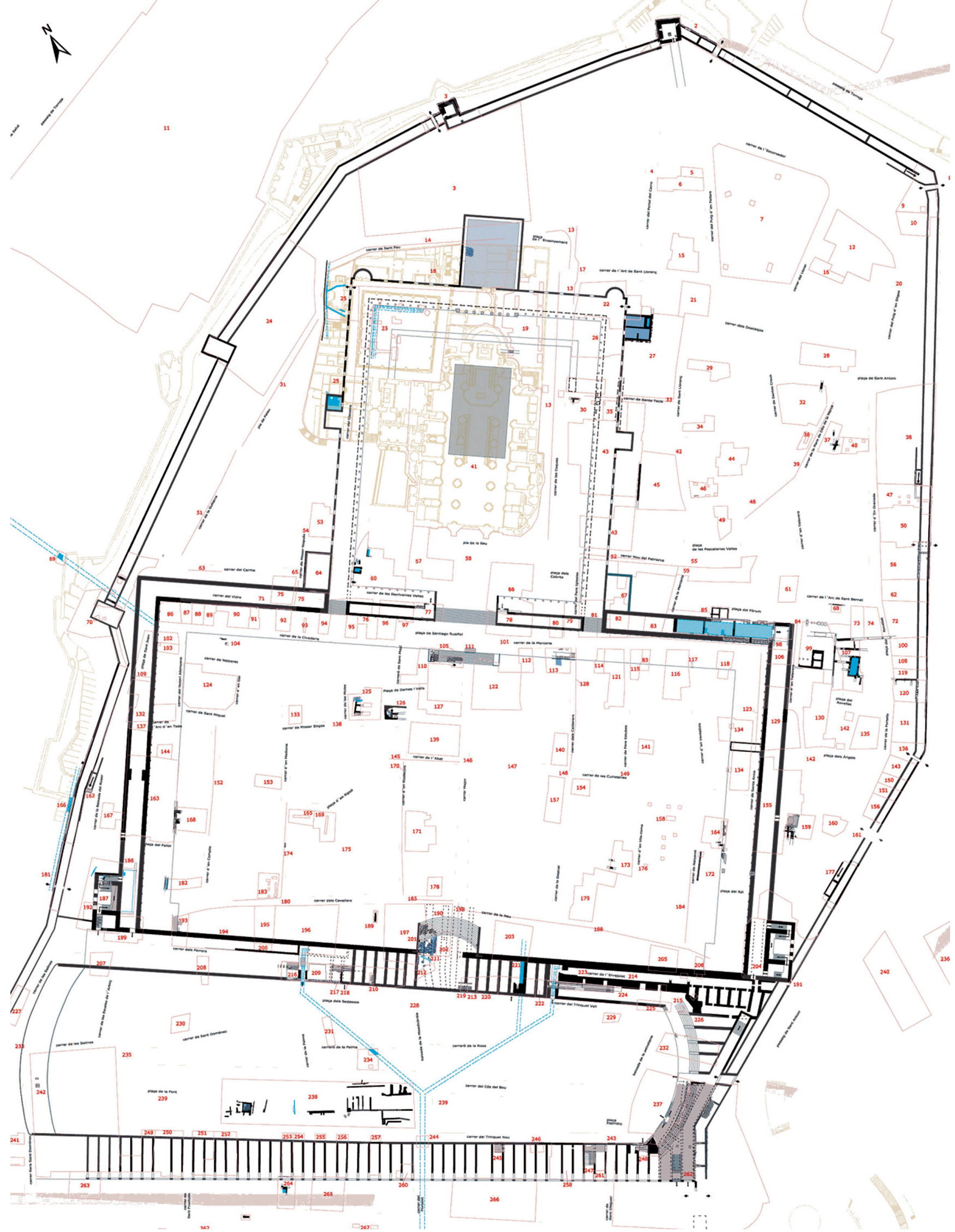

Fig. 6. Planta de la Part Alta de Tarragona 


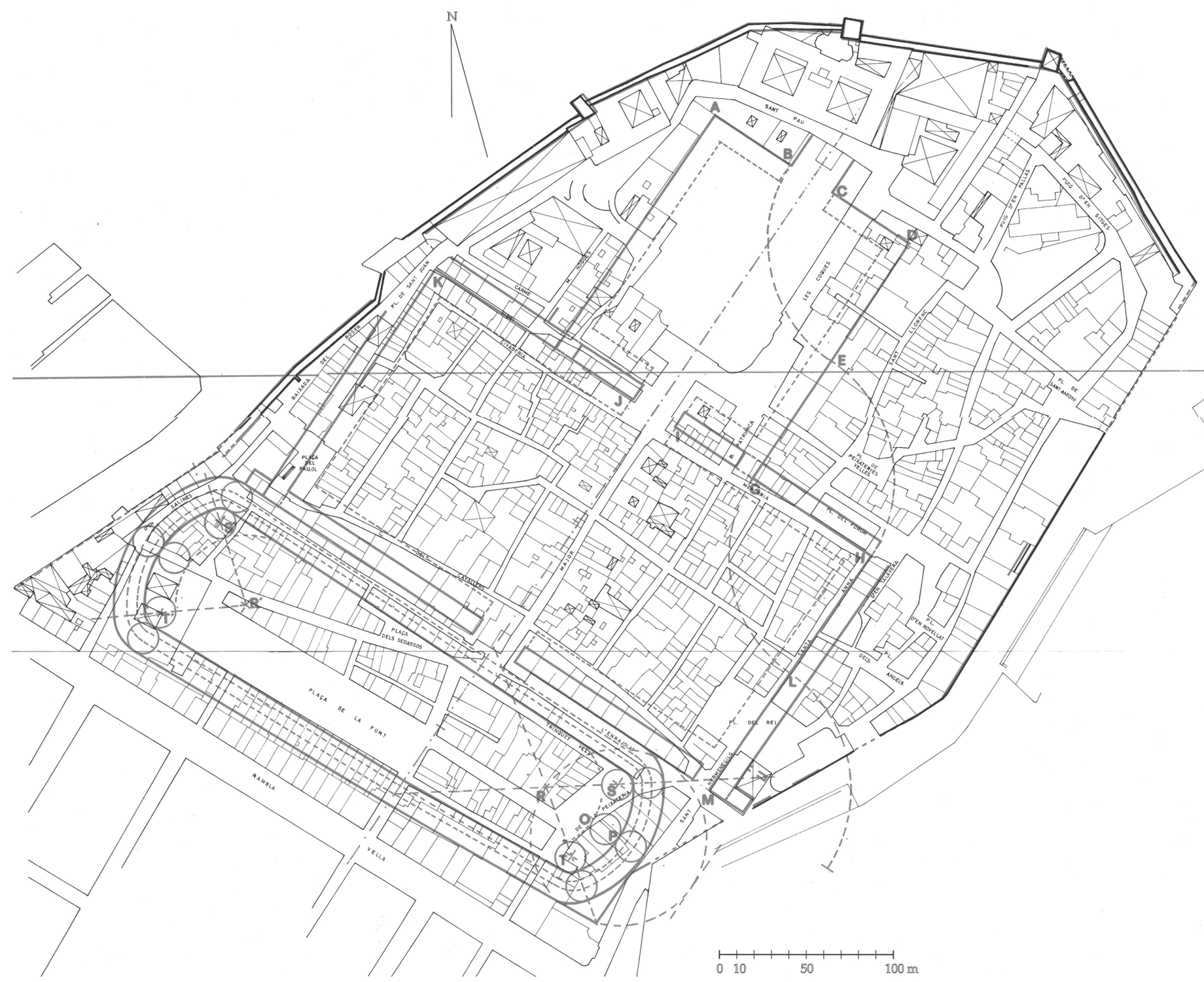

Fig. 7. Esquema constructivo de la Part Alta según Cortés y Gabriel 1993

arquitectura. Después ya vendrán los problemas de capacidad técnica, organizativa y económica, los condicionantes físicos del lugar dónde se implanta la obra, los factores sociales, económicos y históricos, el paso del tiempo, etc, factores que desvirtuarán, en un grado u otro, ese modelo teórico incial. No obstante, todo esto es a menudo posible de reconstruir, de definir cómo se quería que fuese esa forma original. $Y$ es esto lo que se busca cuando se hace el estudio de las formas y proporciones de un edificio: intentar ver que es lo qué se quería hacer, qué implica esta voluntad, cómo se ha construido, qué modificaciones ha sufrido y por qué las ha sufrido.

Una última precisión. Hay un elemento temporal que deja rastros difíciles de percibir y complicados de entender, que influye en gran medida tanto en la forma como en la conceptualización del edificio: el proceso constructivo. Y más si consideramos que en la arquitectura romana este puede llegar a tener tanta importancia, si no más, que la propia obra en $s 1^{15}$. Remarcamos este hecho porque a menudo la presencia de determinados elementos o formas solo se pueden entender desde esa perspectiva, así como el uso de determinados materiales o técnicas que se antojan económicamente inviables o extremadamente costosos.

${ }^{15}$ A nivel ilustrativo, recordar la construcción, por parte de Cesar, del puente sobre el Rin, construcción de escaso valor militar o estratégico, pero realizado con ánimo de demostrar la capacidad romana (De Bellico Gallico 4 17-18). Igualmente significativo son las numerosas imágenes de construcción de fortalezas y edificios presentes en la columna trajana. O el grabado Torlonia del Fucino, que representa los trabajos constructivos de la famosa galería, pero no la galería en sí. 


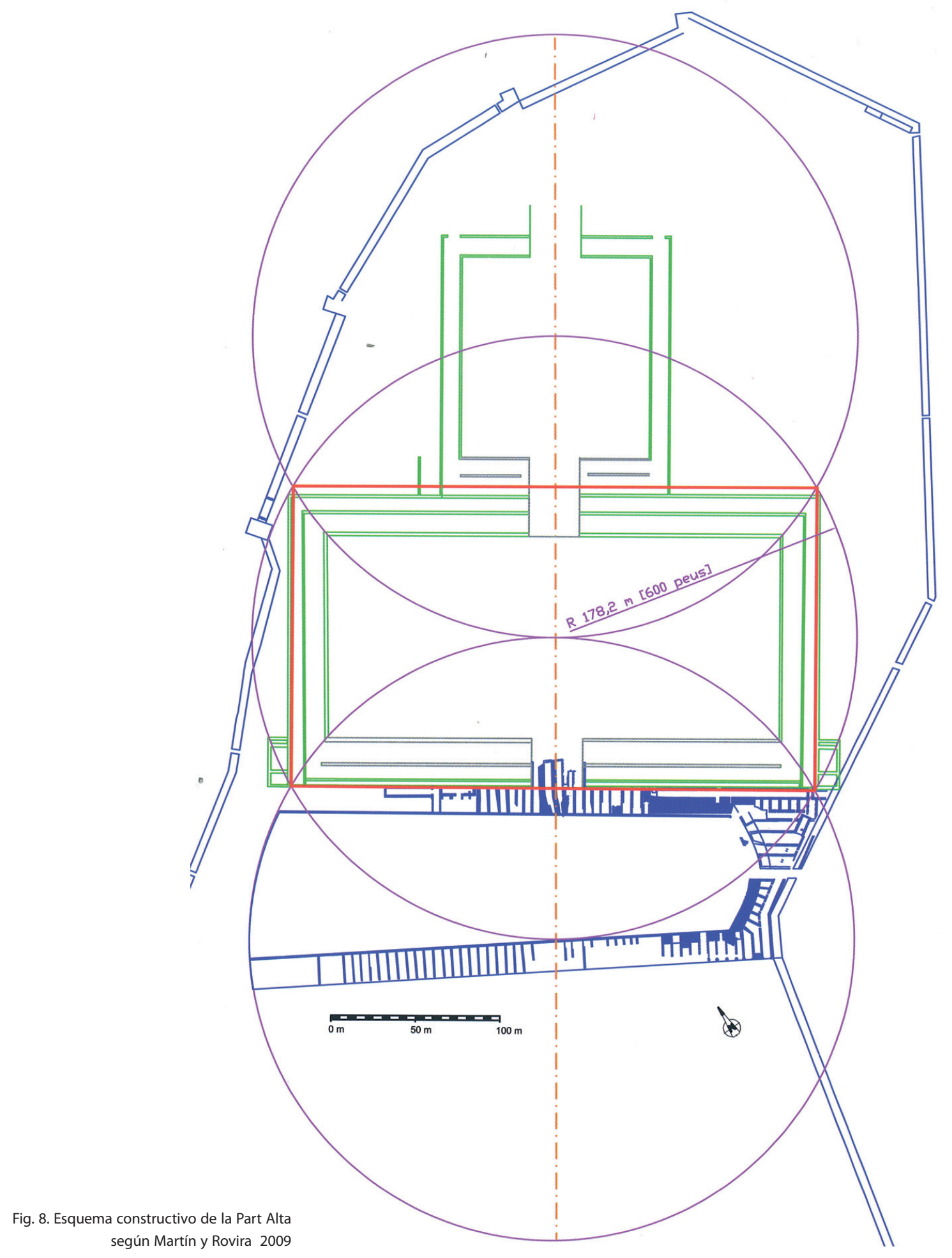

\section{LA PROPORCIÓN DE LA PART ALTA DE TARRAGONA ${ }^{16}$}

En la antigua Tarraco, en lo que ahora se conoce como Part Alta, existía el denominado Concilium Prouinciae Hispa-

${ }^{16}$ La propuesta y su justificación de la disposición formal de la Part Alta de Tarragona que se presenta en este artículo es un resumen de lo ya publicado sobre este tema (Puche et alii 2007). A menos que se indique lo contrario, toda la niae Citerioris (CPHC) (Fig. 6). Es un conjunto arquitectónico conocido de antiguo y repetidamente estudiado desde varias ópticas que, no obstante, se han centrado

planimetría referida a la Part Alta de Tarragona proviene de la publicación de la Planimetria Arqueologica de Tarragona (Macias et alii 2007) o es una reelaboración de la misma. 
mayoritariamente en los proyectos decorativos, en la cuestión cronológica y en la definición y descripción de los espacios $^{17}$. Sólo conocemos dos intentos de estudio compositivo diversos al nuestro, el realizado por Cortes y Gabriel (1981) y otro publicado recientemente (Martín y Rovira 2009). El primero, al estar basado sobre la planimetría disponible en ese momento, claramente insuficiente y errónea, presentaba unas conclusiones muy limitadas (Fig. 7). Aunque se debe reconocer que pese a esos grandes inconvenientes consiguieron definir un discurso lógico y coherente.

Más compleja y elaborada es la propuesta de Martín y Rovira (2009). De hecho, con ella han realizado una monografía que aporta interesantes elementos de discusión, llegando a conclusiones sensiblemente diferentes a las nuestras. Estos autores proponen una modulación basada en el uso de la raíz de 3 a través de la construcción a partir de la vesica piscis y el uso de un módulo de 100 pedes de longitud (Fig. 8), con lo que justifican la forma de la realidad arqueológica conocida ${ }^{18}$.

Tanto esta última publicación, como nuestra propuesta, se ha podido realizar gracias al progreso en la investigación arqueológica de estos últimos años $y$, fundamentalmente, a la publicación de la planimetría arqueológica de Tarragona (Macias et alii 2007), la cual ha permitido posicionar correctamente la totalidad de elementos conocidos que forman parte de este gran complejo arquitectónico.

Las conclusiones de los diversos trabajos realizados en el último tercio del siglo pasado hacían presumir un complejo de proyección unitaria promovido y realizado bajo la dinastía flavia ${ }^{19}$. El área del templo, la gran plaza de representación y el circo serían partes integrantes de un único proyecto ideado con la llegada de los flavios al poder en el año 69 d.C. y finalizado bajo Domiciano. El hallazgo de diferentes elementos de decoración arquitectónica monumental de clara filiación julio-claudia y la

\footnotetext{
${ }^{17}$ Ver, principalmente, T’EDA (1990), Mar (1993), Pensabene y Mar (2009) y Macias et alii (2007b).

${ }^{18}$ No es este ni el lugar, ni nuestra intención, para entablar una discusión en profundidad entre su propuesta y la nuestra, pero la consideramos insuficiente por estar poco argumentada. Las explicaciones a las divergencias entre el modelo y la realidad (que llega a los 6 metros) padecen de una gran carga subjetiva. Además no se aprecia la enorme dificultad de construcción geométrica que comporta conjugar un rectángulo de base raíz de 3 con una modulación interna de base decimal. Pero como ya habíamos apuntado, su propuesta merece plenamente ser considerada aunque solo sea por cuestionar la validez de la que nosotros proponemos. Sólo a partir de la discusión y de la confrontación de conceptos diferentes se podrá avanzar en el conocimiento de este tema.

${ }_{19} \mathrm{Al}$ respecto, cabe destacar la síntesis cronológica y la aproximación a la reconstrucción del complejo decorativo realizado por Mar (1993).
}

existencia de grandes estructuras anteriores planteaban una problemática nunca bien resuelta ${ }^{20}$. De hecho, la inercia de la investigación, que desde los años 80 del siglo pasado se ha había centrado básicamente en el aparato decorativo, ha hecho que estos elementos discordantes hayan sido, a la hora de la verdad y hasta tiempo reciente, si no ignorados, al menos sí poco considerados, y que serias propuestas que explicaban su existencia no tuvieran la proyección esperada.

Se daba por descontado que el gran complejo arquitectónico era, sin duda, una obra flavia y todos los datos arqueológicos venían interpretados y analizados bajo la perspectiva de este axioma. Recientemente, a partir de las últimas excavaciones arqueológicas en la catedral de Tarragona y de un análisis crítico de los datos conocidos, se ha propuesto y justificado de forma coherente una explicación a la presencia de los elementos arqueológicos preflavios. Se propuso la existencia de dos proyectos de monumentalización en la Part Alta de Tarragona (Macias et alii 2007b y Macias et alii, en prensa): uno de julioclaudio seguramente inacabado y otro flavio.

\section{EL PROCESO CONSTRUCTIVO. EL TIEMPO DE CONSTRUCCIÓN}

Es indudable, dada la magnitud y magnificencia de la obra, que la ejecución y materialización de la monumentalización de la Part Alta de Tarraco tuvo que seguir un proceso complejo y dilatado temporalmente, mutante y que debió de condicionar la forma final de la obra.

No es difícil imaginar, aunque por el momento imposible de cuantificar, el impacto que debió tener la construcción del CPHC en la ciudad, relativamente pequeña, de Tarraco. La notable presencia continuada de obreros y especialistas, el constante ir y venir de materiales constructivos (desde la madera hasta la piedra o la cal), la llegada de abundantes materiales líticos de importación, los equipamientos necesarios para mantener a los constructores y dotarlos de las herramientas necesarias y las infraestructuras creadas expresamente para la obra ${ }^{21}$, y todo en un largo periodo de tiempo, tuvo que marcar profundamente la cotidianidad de la ciudad y influir en su economía y en su idiosincrasia.

\footnotetext{
${ }^{20}$ Ya los trabajos de T’EDA (1989), Dupré y Subías (1993) y Rovira (1993), entre otros, constataban estos elementos sin lograr dar una explicación lo suficientemente coherente y argumentada a su existencia.

${ }^{21}$ Es difícil pensar en el acopio de los metros cúbicos de piedra necesarios sin la existencia de una infraestructura ad hoc que permitiese su llegada sea desde las canteras, sea desde el puerto. Sin contar que, probablemente, se construyese un acueducto ex profeso para dotar de agua al complejo.
} 
En la praxis arquitectónica hay un elemento vital que afecta a la correspondencia real entre el proyecto inicial y la obra una vez finalizada: el tiempo. Tiempo para definir cómo debe ser y cómo se quiere el edificio y el tiempo que se necesita para hacerlo realidad. Cuando mayor sea el tiempo, más posibilidades de divergencia podremos encontrar. Sería de esperar que en una obra tan compleja como la nuestra se requiriese, necesariamente, un largo periodo constructivo, siendo la idea inicial susceptible de importantes y significativos cambios o modificaciones. Más si se considera que los grandes proyectos arquitectónicos romanos dejaban amplio espacio a la improvisación (Taylor 2003, 37-38).

Cuantificar el tiempo aproximado de ejecución de una construcción es siempre difícil, pues hay muchos factores aleatorios en juego: la complejidad de la obra, los conocimientos técnicos, la disponibilidad de mano de obra o de materiales, la capacidad organizativa y económica, los cambios de voluntad o, incluso, de los promotores, etc. Sin embargo, sí que se puede hacer una idea de la magnitud del tiempo que en época clásica se podía necesitar por construir un edificio monumenta ${ }^{22}$; El teatro de Pompeyo en Roma se hizo en 6 años, la basílica Iulia en 8, el anfiteatro flavio entre 8 y 10, la galería del Fucino en 11, la aqua claudia en 14, el foro transitorio en 15, la Porticus Aemilius en 20. Para construir el foro de César se necesitaron 25 años (Morselli y Torrorici 1989, 222). El puente Emilius de Roma se terminó después de 30 años, el foro de augusto tardó 40 en finalizarse (Giuliani 2006 y Coarelli 1994) y la Curia Iulia $15^{23}$ (Morselli y Torrorici 1989, 43). En esos tiempos, según noticias contemporáneas a las obras, casi nunca se contabilizan los trabajos previos de estudio y redacción del proyecto. Todos los ejemplos referidos hacen mención a obras realizadas en Italia, donde la capacidad y voluntad del poder imperante es, indiscutiblemente, muy fuerte. Solo así se entiende que una obra como el coliseo se terminase en menos de 10 años, o que durante el reino de Claudio se realizasen, simultáneamente, diversas obras de gran magnitud (Galeria del Fucino, puerto di Claudio en Ostia, canalización del Tíber, los acueductos de l'Aqua Claudio y del Anio Novus ${ }^{24}$ ). Pero son indicativos de los tiempos necesarios para completar grandes obras monumentales.

22 Casi toda la información referida a los tiempos de construcción hacen referencias a obras realizadas en Roma o en Italia.

23 Se tiene que considerar las dimensiones relativamente reducidas de este edificio, aprox. $24 \times 27$ metros, que vienen a ser unos $650 \mathrm{~m}^{2}$.

${ }^{24}$ Las fuentes hablan de más de 30.000 obreros durante 20 años trabajando directamente en Portus y otros 30.000 en la galería del Fucino (Svetonio De vita caesarum Claudio XX).
Lejos de Roma, donde no había los mismos recursos que en la capital ni un poder decisivo tan importante, la ejecución de grandes obras públicas seria más susceptible de sufrir problemas y retrasos importantes. Tenemos, como ejemplos, la construcción del acueducto de Nicodemia, según explica Plinio el Joven (Hist. Nat. X, 37$38)^{25}$. En una carta enviada al emperador Trajano, explica los dos intentos fallidos de esta ciudad en la construcción de un acueducto en la que han invertido inmensas sumas de dinero, por lo cual pide la ayuda directa del emperador. Intentos en los que se llega a construir un largo tramo de arcuaciones que posteriormente viene desmontado, para construir uno nuevo, el cual, a su vez, también resulta inutilizable. Quizás más ilustrativo sea la construcción en el 137 d.C. de un túnel de 482 metros de longitud para el acueducto de Saldae (actual Bejaia, Argelia), donde se requirieron los servicios de Nonio Dato, un librator militar que redactó el proyecto e inició las obras. Diez años más tarde, fue llamado de nuevo ya que las obras de perforación iban francamente mal (CIL VIII, 2728), resolviendo estos problemas, de tal manera que en el 151-152 d.C. (14 años más tarde) se pudo finalmente inaugurar el acueducto.

En definitiva, se puede determinar que en época clásica el tiempo de construcción de las grandes obras públicas podría contarse más por lustros que por años.

En el caso de Tarragona, apenas disponemos de noticias históricas o epigráficas que nos puedan orientar sobre el tiempo empleado en la construcción de todo el complejo monumental ${ }^{26}$. Sólo tenemos la noticia de Tácito (Tácito, Ann Y, 78, templum ut in colonia Tarraconensi strueretur Augusto petentibus Hispanis permissum, datumque in omnis prouincias exemplum) sobre la voluntad de Tarraco de levantar un templo dedicado a Augusto en el año 15 d.C. Por otro lado, tenemos la opinión de varios autores (Alföldy 1991, 46; Aquilue y Dupré 1986, 5 y T’EDA 1989, 84) de que, de acuerdo a la epigrafía y a los resultados de determinadas excavaciones arqueológicas, el $\mathrm{CPHC}$ ya estaba en funcionamiento durante el reinado de Vespasiano (69-79). No deja de ser indicativo el dato aportado por Alföldy sobre el inicio de la colocación de basamentos de estatuas ya desde la año 70 (Alföldy 1991,

\footnotetext{
${ }^{25}$ In aquae ductum, domine, Nicomedenses impenderunt HS XXX CCCXVIII, qui imperfectus adhuc omissus, destructus etiam est; rursus in alium ductum erogata sunt CC. Hoc quoque relicto novo impendio est opus, ut aquam habeant, qui tantam pecuniam male perdiderunt... Sed in primis necessarium est mitti a te vel aquilegem vel architectum, ne rursus eveniat quod accidit. Ego illud unum affirmo, et utilitatem operis et pulchritudinem saeculo tuo esse dignissimam.

${ }^{26}$ Sobre la cronologia constructiva del recinto de culto, ver Macias et alii (en prensa).
} 
38), proponiéndose esta fecha como el inicio de las actividades religiosas (Rovira 1993, 208). Esta datación se da por definitiva y los autores posteriores aceptan como fecha de construcción del CPHC un momento cercano al año 70 d.C. (Remolà y Pociña 1999, 27), colocando el monumento dentro los grandes proyectos edilicios de época flavia.

Hay, sin embargo, un elemento de praxis arquitectónica que entra en clara contradicción con este precepto. Si se considera que el CPHC es un monumento de proyección y concepción Flavia, es materialmente imposible que éste pueda estar en funcionamiento (aunque sea de forma provisional) alrededor del año 70. La dinastía flavia llega al poder el año 68, pero no se consolida hasta Vespasiano (69-79). Y una obra de tal magnitud, la cual afecta a más de 12 hectáreas con un importante volumen de movimiento de tierras y de obra constructiva, necesita a la fuerza un periodo de proyección y ejecución bastante elevado que, en ningún caso, puede ser inferior a un lustro. $\mathrm{O}$ una de dos, o nos encontramos con un proyecto iniciado en época Julio-Claudia, o la construcción del CPHC se debería situar en época flavia avanzada. Como las evidencias arqueológicas y epigráficas insisten en indicar una construcción Vespasiana inicial, o quizás ligeramente anterior (Macias et alii $2007 \mathrm{~b}, 774)^{27}$, a la fuerza se debe pensar en una proyección o inicio de la construcción en época julioclaudia.

Las excavaciones llevadas a término los años 90 en la Plaça de la Font (AA.VV. 1999 y Gebellí 1999), lugar dónde se ubicó la arena del circo, pueden ser bastante significativas para ayudar a establecer la lógica del marco temporal en que se desarrolló la construcción del CPHC. Se descubrió una figlina y áreas de extracción de arcillas, que fueron amortizadas en un momento cercano al año 60 , con un terraplén que regularizaba completamente el terreno, casi con toda seguridad como parte del trabajo necesario previo a la construcción de la arena (López y Piñol 2008, 17). Sobre este terraplén se documentan pequeños niveles de nivelación y la construcción de estructuras de carácter precario, las cuales desaparecen en época de Domiciano, cuando se finaliza la construcción del circo. Parecería evidente que nos encontramos ante los trabajos previos a la construcción del circo, pudiéndose interpretar las estructuras murarias localizadas como

\footnotetext{
${ }^{27}$ Sorprende la carencia de crítica que a veces muestran determinados autores ante conjuntos arqueológicos constructivos que podrían ser datados en época neroniana, pero que se sitúan en época flavia con la argumentación, auto justificada, que al ser la construcción de época flavia, los niveles constructivos tienen que ser, por lógica, también flavios (Remolà y Pociña 1999, nota 21).
}

los restos de las instalaciones de las infraestructuras de la obra $^{28}$. Una construcción de las dimensiones del CPHC debe requerir un amplio espacio en el que colocar el campamento para instalar las barracas de los trabajadores, los talleres de reparación y construcción de maquinaria, las zonas de almacenamiento y de control de todos los trabajos... Y el espacio que ocupará el circo parecería, a priori, idóneo a tales efectos: tiene una gran extensión, en ella no se ha proyectado ninguna construcción y se dispone en la zona más adecuada para no entorpecer los trabajos y para que las partes completadas no dificulten lo que tuvo que ser un intenso y constante movimiento de personas y materiales.

Bajo esta perspectiva, se deduciría que en el circo, en un momento cercano al año 60 d.C., ya se habrían iniciado los grandes trabajos constructivos en esta zona con la realización de los movimientos de tierras necesarios, trabajos que finalizarían a finales de los siglo I d.C. (Dupre et alii 1988). Como se verá más adelante, el circo forma parte indiscutible de todo el proyecto del CPHC, y por lo tanto, si los trabajos preparatorios para su construcción se sitúan alrededor de los años 60 , se debe considerar, en plena lógica, que el proyecto constructivo de todo este monumento seria una obra finalizada en época flavia, pero que respondería a un proyecto iniciado durante la dinastía julio-claudia ${ }^{29}$.

Es evidente que no se pueden descartar todas las otras evidencias que indican claramente una fase constructiva flavia y que situarían dentro de esta cronología la mayor parte de estructuras arquitectónicas visibles del $\mathrm{CPHC}$, lo que nos llegaría a establecer una dinámica constructiva compleja y cronológicamente evolucionada.

Esta dinámica ya ha sido expuesta (Macias et alii 2007b y Macias et alii en prensa) describiéndose la existencia de dos proyectos constructivos diferenciados en la Part Alta de Tarragona. Uno, de época julio-claudia, seguramente no finalizado, y otro segundo de época flavia. Faltaría por definir dónde acaba el primero y dónde empieza el segundo, cuál sería su aspecto inicial y qué elementos serían aprovechados por el segundo proyecto.

\footnotetext{
${ }^{28}$ El estudio completo de esta excavación está en vías de publicación. Su autor, Gebellí, comparte la misma opinión sobre la interpretación de estas estructuras, confirmando (aunque ajustando) una cronología julio-claudia. Agradezco a este autor sus indicaciones y comentarios al respecto.

${ }^{29}$ Esta cronología inicial es muy coherente con determinados niveles constructivos de la Torre de l'Audiència (T'EDA 1989, 181), con numerosos fragmentos de decoración arquitectónica (Alföldy 1991, Hauschild 1983 y Pensabene 2005) y, quizás, con los niveles constructivos de la calle Comte 12/14 (Remolà y Pociña 1999).
} 


\section{LAS FORMAS Y MEDIDAS}

Tal y como se ha indicado anteriormente, la realización de la planimetría arqueológica de Tarragona ha permitido situar con gran exactitud (Macias et alii 2007) todos los elementos arquitectónicos arqueológicos conocidos hasta el momento actual ${ }^{30}$ (Fig. 9).

Una primera lectura y estudio de las estructuras conservadas y conocidas permiten agruparlas en tres grupos a partir de las orientaciones que presentan. De hecho, no deja de ser curioso observar este fenómeno en una construcción ortogonal como la nuestra y esto debe responder, necesariamente, a una casuística determinada y a la existencia de diversos proyectos constructivos (Macias et alii 2007 y Macias et alii en prensa).

La primera la encontramos en la fachada septentrional del circo y en la figlina que había debajo de lo que después será la arena del circo. Corresponde a la orientación general de la ciudad republicana, y por lo tanto están en relación directa con ella (Macias 1999).

La segunda alienación la encontramos en la gran zanja descubierta por Sánchez Real (1969) y Hauschild (1983) en el claustro y el cementerio viejo de la catedral, en la conocida como Volta Llarga, construida con anterioridad al circo, y en el gran muro de sillares situado debajo del Pretori y detrás de la grada septentrional del circo (Dupré y Subías 1993 y Piñol 2000). La encontramos, también, en el cierre occidental de la plaza de representación y quizás en la galería de la calle Civaderia (Bermúdez 1992) ${ }^{31}$.

A la tercera alineación corresponden la mayor parte de las estructuras conocidas que configuran el grueso del actual conjunto monumental. Aquí se observa que tanto las medidas lineales como las angulares presentan un grado de precisión altísimo, con un error estimado que no supera el uno por ciento. Los errores angulares detectados, tanto de las esquinas de la plaza de representación como del témenos del templo, se miden más en segundos que no en minutos. En concordancia, las medidas lineales presentan el mismo grado de exactitud. Así, observamos que la medida interior de la parte superior de la plaza de representación es de 295,75 metros, que son 999,1 pedes 32 (Macias et alii 2007, fig. 22), valor demasiado próximo a los 1.000 pedes como para no ser intencionado. Esto representa una precisión superior al uno

\footnotetext{
30 Sobre el análisis de las formas y de la modulación de los dos diferentes proyectos ya se realizó una primera aproximación (Puche et alii 2007).

31 Sobre la problemática de su correcto posicionamiento y sobre su técnica constructiva, ver Macias et alii $(2007 \mathrm{~b}, 770)$ y Puche et alii $(2007,42)$.

32 Siempre se ha partido de la hipótesis de la utilización, como unidad de medida, del pie romano clásico, del pes monetalis, de 0,296 m.
}

por mil. Precisiones de esta magnitud las encontramos continuamente. Por eso sorprende la desviación del muro occidental de la plaza de representación, que provoca un error de tres metros (un error del 3\%, 100 veces superior a los errores hasta ahora detectados), razón por la cual creemos que es debido más a una intencionalidad que no a un error de proyección o ejecución.

\section{EL PRIMER PROYECTO CONSTRUCTIVO}

Dentro de este proyecto incorporamos las estructuras que presentan una alineación de $33^{\circ} 28^{\prime} 44^{\prime \prime} \mathrm{E}-146^{\circ} 31^{\prime} 56^{\prime \prime}$ W y que, arqueológicamente, corresponden a elementos estratigráficamente anteriores a las estructuras del que conocemos como C.P.H.C (Fig. 10).

Uno de los elementos más significativos y que más información aporta a la comprensión de este proyecto es la gran zanja descubierta por Hauschild y Sánchez-Real en el claustro de la catedral (Macias et alii 2007, ficha 23). Mide 90,7 metros de largo (306 pedes) por 3,07 metros (10,4 pedes) de ancho y corresponde a una zanja de cimentación de un muro de grandes dimensiones que podría tener un grueso de entre 6 a 7 pies $^{33}$ (Fig. 10 A). Si fuera así, resultaría que la estructura a la que iba destinada mediría 300 pies de longitud, o lo que es lo mismo, exactamente 2,5 actus. Este muro delimitaría la anchura de un amplio espacio del cual no conocemos su longitud, pero la distancia que lo separa del límite topográfico de la terraza, dónde actualmente están las escaleras de la catedral y las bóvedas de la calle Civaderia (Macias et alii 2007, ficha 77 78), es de entre 476 a 478 pies (Fig. 10 C). Esta distancia se aproxima mucho a los 4 actus (480 pies), de la cual sólo diverge un $1 \%$ (Fig. 13).

Una coincidencia (o no) a destacar y que quizás reforzaría la idea de que la longitud de este espacio fuera de 4 actus es que la relación que se establece con su anchura (2,5 actus) se aproxima mucho, demasiado para ignorarse, a la relación aurea $(4 / 2,5=1,6$, siendo $1,6 \varphi)$. Y precisamente esta es la misma proporción que se propone en las últimas reconstrucciones del templo de Augusto para el cual se suponen unas medidas de 44 por 27 metros (44/ $27=1,6=\varphi$, Pensabene y Mar, 2009) (Fig. 10 B).

Otro elemento arquitectónico correspondiente a este primer proyecto es un gran muro de sillares, con una potente cimentación de caementicium, situado entre la gran plaza de representación y el circo (Macias et alii 2007,

\footnotetext{
${ }^{3}$ Esta zanja se ha interpretado como un proyecto no finalizado (Hauschild 1983). Recientemente se ha supuesto que corresponde a la cimentación de un primer témenos del templo de Augusto (Pensabene y Mar 2004 y 2009).
} 


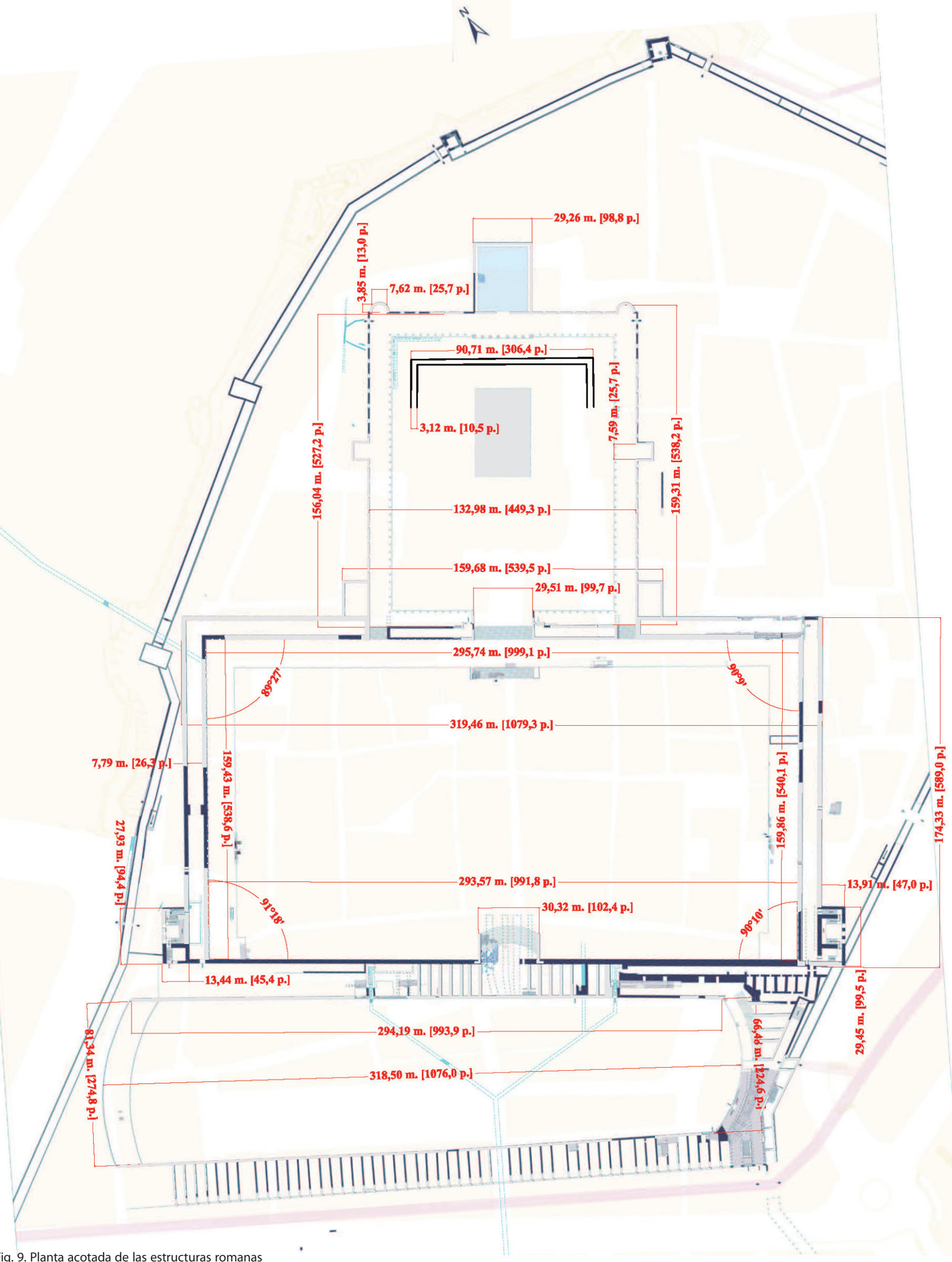

Fig. 9. Planta acotada de las estructuras romanas 
fichas 204, 205, 206, 216, 220 y 221) del que se ha documentado una longitud mínima de 250 metros de largo (Fig. 10 E). Este sería el muro de contención que marcaría el límite inferior de la plaza de representación y que, a la altura de la torre del Pretori, giraría en dirección Noreste, justo después de presentar una puerta de más de 2 metros de anchura (Macias et alii 2007, ficha 204). Su construcción es claramente anterior al circo y a las estructuras flavias del CHPC (Dupré y Subías 1993) y presenta una serie de marcas de cantería que situarían su construcción en torno al año 39 d.C. (Piñol, inédito citado en Macias et alii 2007b, 770).

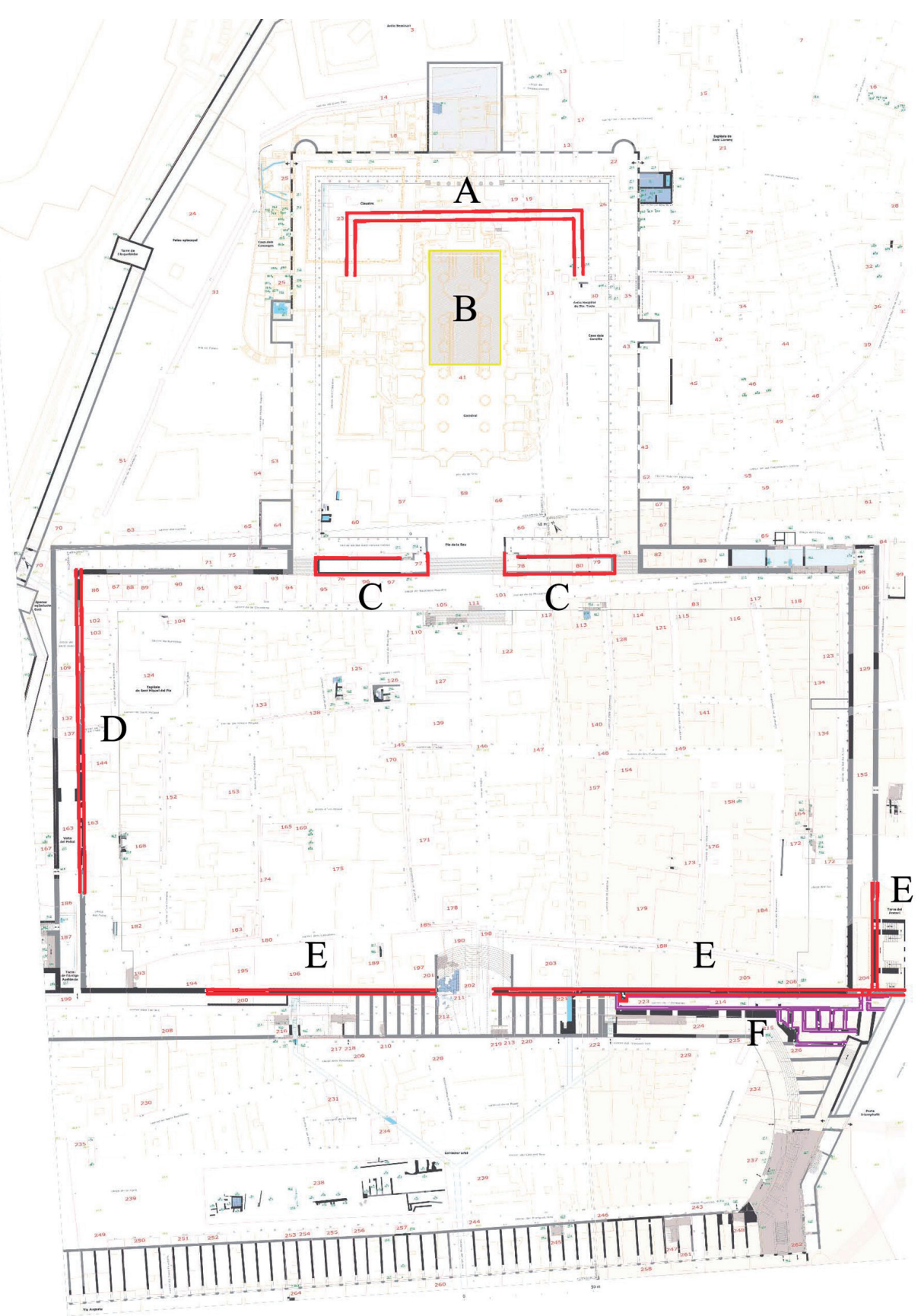

Fig. 10. Estructuras del primer proyecto constructivo. A. Gran trinchera del claustro de la catedral. B. Posible ubicación del templo de Augusto. C. Estructuras de la calle Civaderies. Posibles «propileos». D. Rebaje occidental de la plaza de representación. E. Gran muro de sillares de contención de la plaza de representación. F. Sistema de bóvedas adosado al muro de sillares y anterior a la construcción del circo 


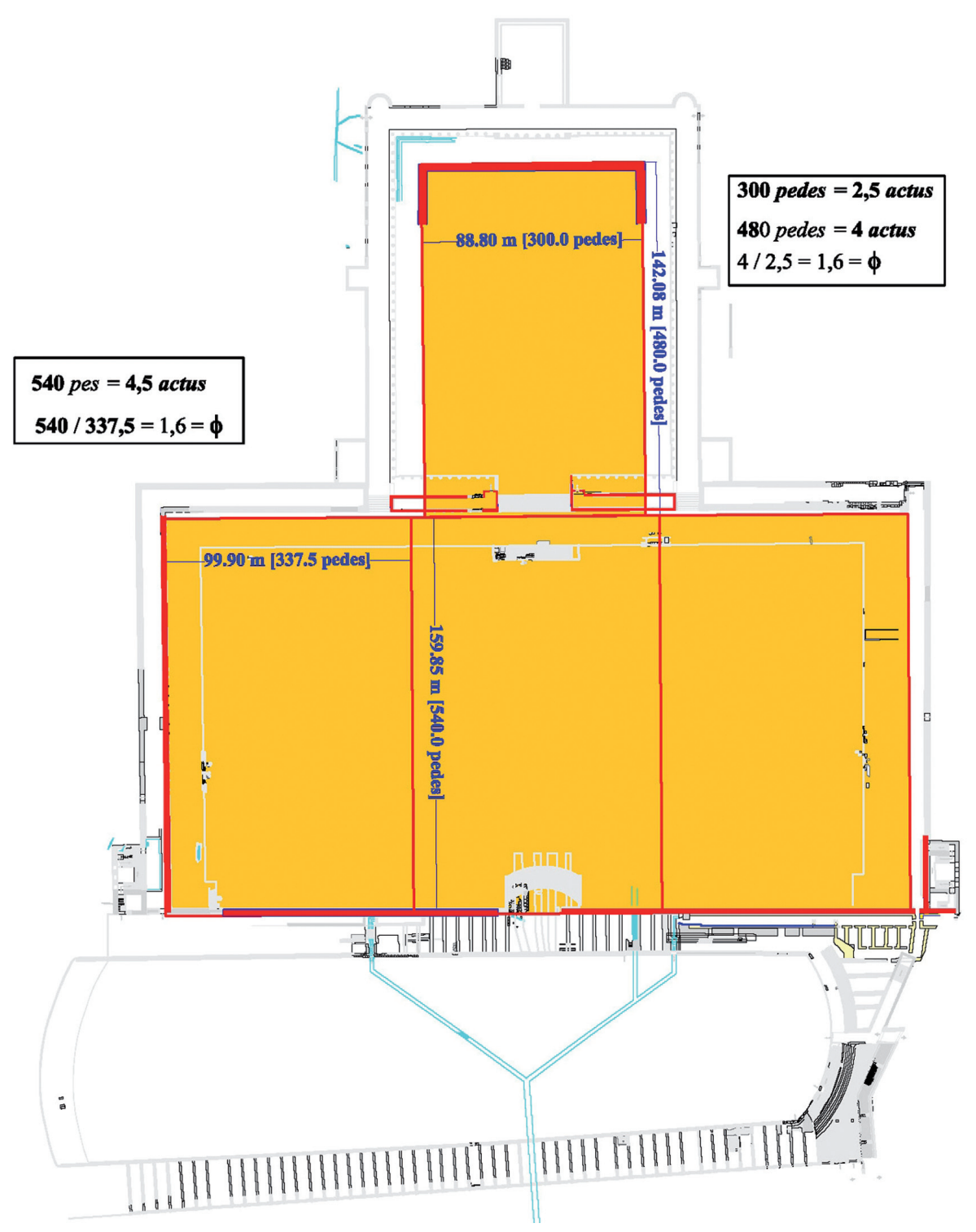

Fig. 11. Medidas y modulación del primer proyecto constructivo

Perpendicular a este muro encontramos la alineación del lado oeste de la plaza de representación (Fig 10 D). Aquí no se han documentado estructuras preflavias ${ }^{34}$, pero el hecho que este lado sea ortogonal al muro de sillares y que sea el único elemento de la fase flavia que se descuadra puede hacer pensar en la fosilización de estructuras precedentes.

La distancia que hay entre el muro de sillares (Fig. 10 E) y el criptopórtico de la calle Civaderia (Fig. 10 C) es de 540 pedes (159,9 metros) o, lo que es lo mismo, 4,5 actus. La anchura de este espacio estaría definida por el ángulo del muro de sillares situado debajo del Pretori y la

\footnotetext{
${ }^{34}$ Aunque hay posibles niveles constructivos neronianos en la calle Comte 12/14.
}

estructura que fosiliza el muro occidental de la gran plaza de representación (Fig. 10 D), con una distancia aproximada de 1.020 pedes, correspondientes a unos 8,5 actus. Si aplicamos el principio de proporcionalidad, hallamos que el espacio descrito anteriormente se puede definir a partir de tres rectángulos de 540×340 pedes, que presentan también una proporción aurea (Fig. 11).

En resumen, y con los datos actualmente conocidos, se puede proponer la existencia de un primer proyecto de monumentalización que afectaría al entorno del área del templo dedicado a Augusto (terraza superior, Fig 10 B), al lado del cual y a una cota inferior se define un gran área rectangular aterrazada, ignorándose el uso del espacio que posteriormente ocuparía el circo. No obstante, la presencia 
de niveles y estructuras Claudio-Neronianas documentadas en las excavaciones de la plaza de la Font hacen pensar que ese espacio estaba plenamente afectado, de una forma $\mathrm{u}$ otra, por todo el proceso constructivo.

Estos espacios se dispondrían en forma de rectángulo y estarían definidos por $a^{c t u s^{35}}$ y estructurados a partir de una proporción aurea.

\section{EL SEGUNDO PROYECTO CONSTRUCTIVO}

Para el segundo proyecto constructivo disponemos de muchos más datos, puesto que corresponde a la monumentalización definitiva de la Part Alta (Fig. 12 y 13). El primer hecho a destacar es la constatación inequívoca del uso de un sistema decimal basado en el pes correctus ${ }^{36}$. Es más evidente en el lado norte de la plaza de representación (Fig. 12 B) que mide 1.000 pedes, exactamente 999, 10, (todas las medidas se han extraído de Macias et alii 2007, fig. 22), medida idéntica a la que parece que tendría la grada norte del $\mathrm{circo}^{37}$. El edificio del Pretori (Fig. 12 a) mide 99,5 pedes de largo, las exedras laterales (Fig. 12 B) de la plaza del templo (Fig. 12 A; Macias et alii 2007, fichas $25,35,43) 25,70$ pedes; el exterior de la sala axial del temenos (Fig. 12 C; Macias et alii 2007, fichas 18-19), 98,80 pedes; la anchura de las escaleras que comunican la plaza de representación con el temenos (Fig. $12 \mathrm{~d}$ ) (Macias et alii 2007, fichas 77,78 ) es de 99,70 pedes; la anchura teórica (que no real, y esto podría explicar la desviación del 2\%) del pulvinar (Fig. 12 E; Macias et alii 2007, fichas 201, 202, 203) es de 102,4 pedes, ${ }^{38}$ etc. Todas ellas, medidas que se aproximan enormemente a múltiplos de base 10 del pes (Fig. 9).

No obstante, la estructura básica parece que se organiza de nuevo en base al actus. Así, tenemos que la distancia que hay entre los muros exteriores del temenos (Fig. $12 \mathrm{~A}$ ) es de 159,68 m, es decir 539,5 pedes, que corresponderían a 4,5 actus $^{39}$, medida que ya hemos constatado en la modulación anterior, por lo que no la consideramos casual.

Una magnitud similar la encontramos entre las exedras circulares del lado norte del temenos (Fig. $12 \mathrm{f}$; Macias et alii 2007, fichas 22, 25) y las bóvedas de la calle

\footnotetext{
${ }^{35}$ No debe extrañar el uso del actus como unidad. No olvidemos que más que un proyecto arquitectónico es un proyecto urbanístico y que la división parcelaria urbana se estructura en función del actus.

${ }^{36}$ Sobre el valor «real» del pes correctus, ver Hultsch (1882), Vázquez Queipo (1859) y Giuliani (1983).

${ }^{37}$ Aquí las medidas se deducen de la restitución teórica de la parte que falta, las carceres, pero da una medida muy coherente con la anterior (993,9 pedes).

${ }^{38}$ Hay que destacar que estos tres elementos, sala axial, escaleras al témenos y pulvinar, además de estar alineados presentan una geometría coherente entre ellos.

39 4,5 actus serían exactamente 540 pedes o, lo que es lo mismo, 159,84 metros.
}

Civaderia (Fig. 12 g; 159,31 m / 538,2 pedes). Esto permitiría inscribir la terraza superior dentro de un cuadrado de 4,5 actus de lado. La sala axial (Fig. 12 c) quedaría fuera de este esquema y seria un elemento (en el sentido geométrico) independiente ${ }^{40}$.

En la plaza de representación (Fig. 12 B) se vuelve a encontrar esta medida entre sus límites septentrional y meridional, repitiendo, como no podía ser de otra manera, las dimensiones del primer proyecto. También nos la encontramos, multiplicada por dos, en la distancia que hay entre los exteriores de los dos criptopórticos de los lados menores (Fig. 12 h, i). Esto indicaría que la plaza de representación vendría definida por dos cuadrados de 4,5 actus de lado (Fig. 13).

En este modelo teórico se encuentran, fundamentalmente, dos discrepancias: la primera, ya mencionada, es la discordancia del lado occidental de la plaza de representación (Fig. 12 i), que rompe la perfección geométrica. Sobre esta ya se ha apuntado la posibilidad de que sea una fosilización del proyecto anterior que, en un grado u otro, ya debía estar materializado en esta zona. No en vano, en esta área, a fin de regularizar el terreno, se tuvo que hacer un importante rebaje de la colina de más de nueve metros de profundidad, en una roca calcárea extremadamente dura (llamada localmente fetge de gat).

La otra contradicción se halla en el hecho de que el módulo escogido incluye la anchura de los criptopórticos laterales (Fig. $12 \mathrm{~h}, \mathrm{i}$ ), pero no el criptopórtico meridional (Fig. 12 j; Macias et alii 2007, fichas 82, 83, 85), que quedaría fuera. Se debe observar que este último sólo existe en la mitad oriental de la plaza de representación (Fig. $12 \mathrm{~B}$; en la actual plaza del Foro), mientras que en la otra mitad la plaza queda delimitada por un acusado rebaje de la colina que hace inviable e innecesario la existencia de un criptopórtico (Macias et alii 2007, 64 y ficha 86). En este caso se debería empezar a considerar el criptopórtico existente (Fig. 12 j) como un elemento de articulación entre la plaza de representación y el espacio, arqueológicamente desconocido (Pensabene 2005), situado al nordeste de la plaza y que por tanto, a nivel compositivo, sería independiente y no intrínseco al diseño geométrico.

Con respecto al módulo cuadrado, volvemos a encontrarlo en el circo (Fig. 12 C), en concreto en las dimensiones del eje de la arena, que teóricamente tendría que medir 1.080 pedes. No tenemos, o no hemos sabido encontrar, ninguna justificación, dentro de este módulo o en otro de

\footnotetext{
${ }^{40}$ No se conoce la profundidad de esta sala. No obstante, el hecho de encontrar la roca recortada debajo de la fachada del seminario haría posible que tuviera una forma cuadrada, que repetiría así el ritmo del resto del área monumental.
} 
Fig. 12. Estructuras del segundo proyecto constructivo. A. Terraza superior, área de culto. B. Plaza de representación. C. Circo. a. Torre del «Pretori». b. Exedras laterales. c. Sala axial. d. Escalas de acceso al área de culto. e. «Pulvinar». f. Exedras circulares. g. Criptoportico de la calle Civaderia. h.

Criptopórtico lateral oriental. i. Criptopórtico lateral occidental. j. Criptopórtico meridional

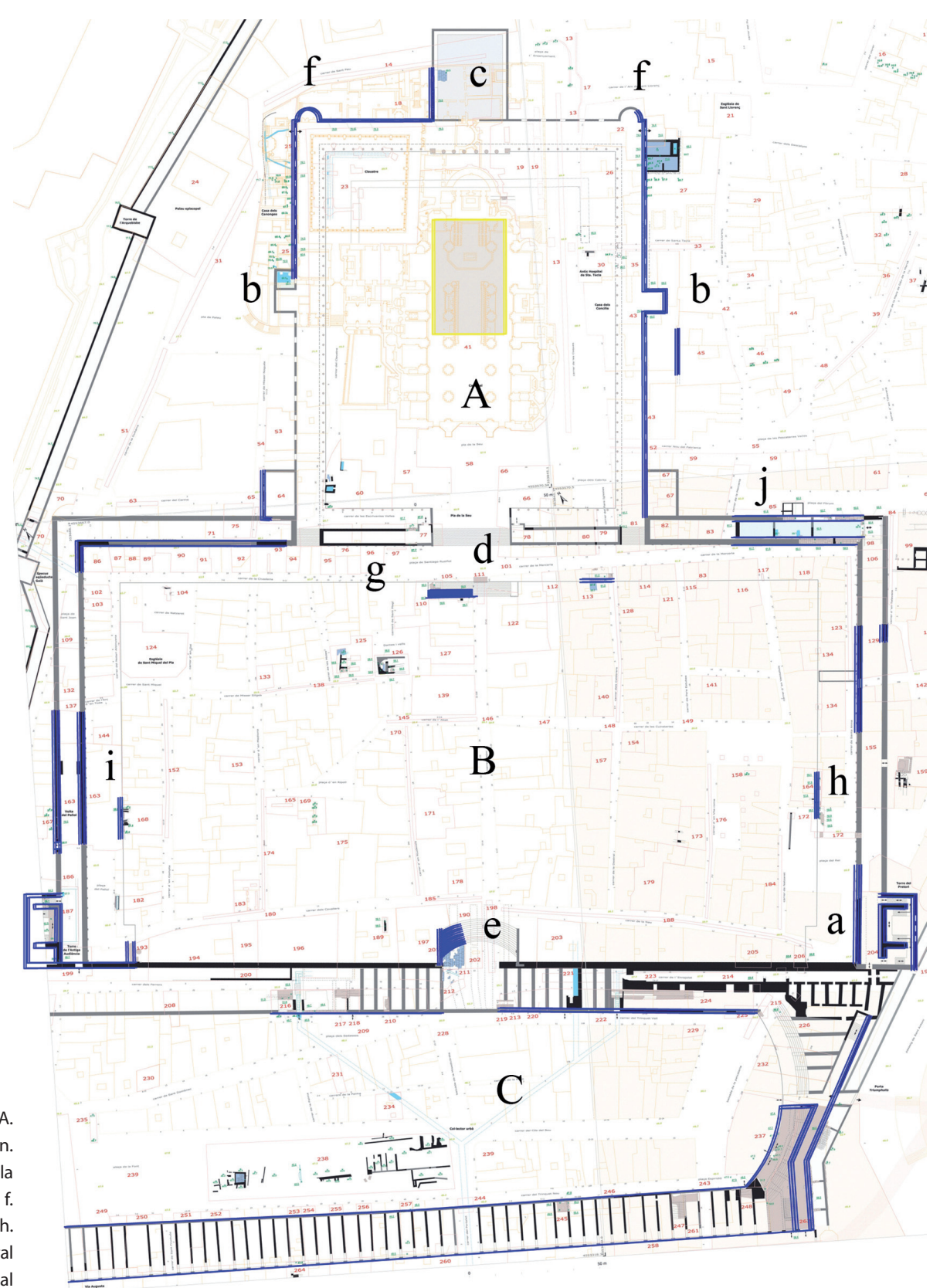

más pequeño, que sirva para definir la anchura de este último edificio ${ }^{41}$. Lo que sí resulta evidente es que su módulo se encuentra desplazado hacia el Oeste, obviamente condicionado por el espacio libre determinado por la muralla y por su función de bisagra con la trama urbana de la ciudad.

En resumen, tendríamos para este proyecto un esquema compositivo organizado con cuadrados de 4,5 actus de lado. Uno superior, dónde estaría el área cultual definido

\footnotetext{
${ }^{41} \mathrm{Al}$ respecto se ha de referir al trabajo de Martín y Rovira, que si encuentran una justificación geométrica a las dimensiones del circo (Martín y Rovira 2009, 35-36). A discutir, pero se ha de reconocer la coherencia de su discurso.
}

por un módulo. Debajo de él se situaría un rectángulo de dos módulos, rectángulo que se repetiría en el circo, aunque descentrado por una razón topográfica (Fig. 14).

Esto, con respecto al esquema general, puesto que se ha podido constatar una modulación interna que describe y justifica los diferentes elementos menores. Se observa así que la anchura formada por el podio y el criptopórtico en la plaza de representación es de 26,66 m., que son exactamente 90,1 pedes, y 90 pedes es $1 / 6$ de 4,5 actus, medida que aparece repetidamente y que nos ha permitido definir un módulo de definición interna de todo el complejo monumental (Fig. 15). El hecho de que 


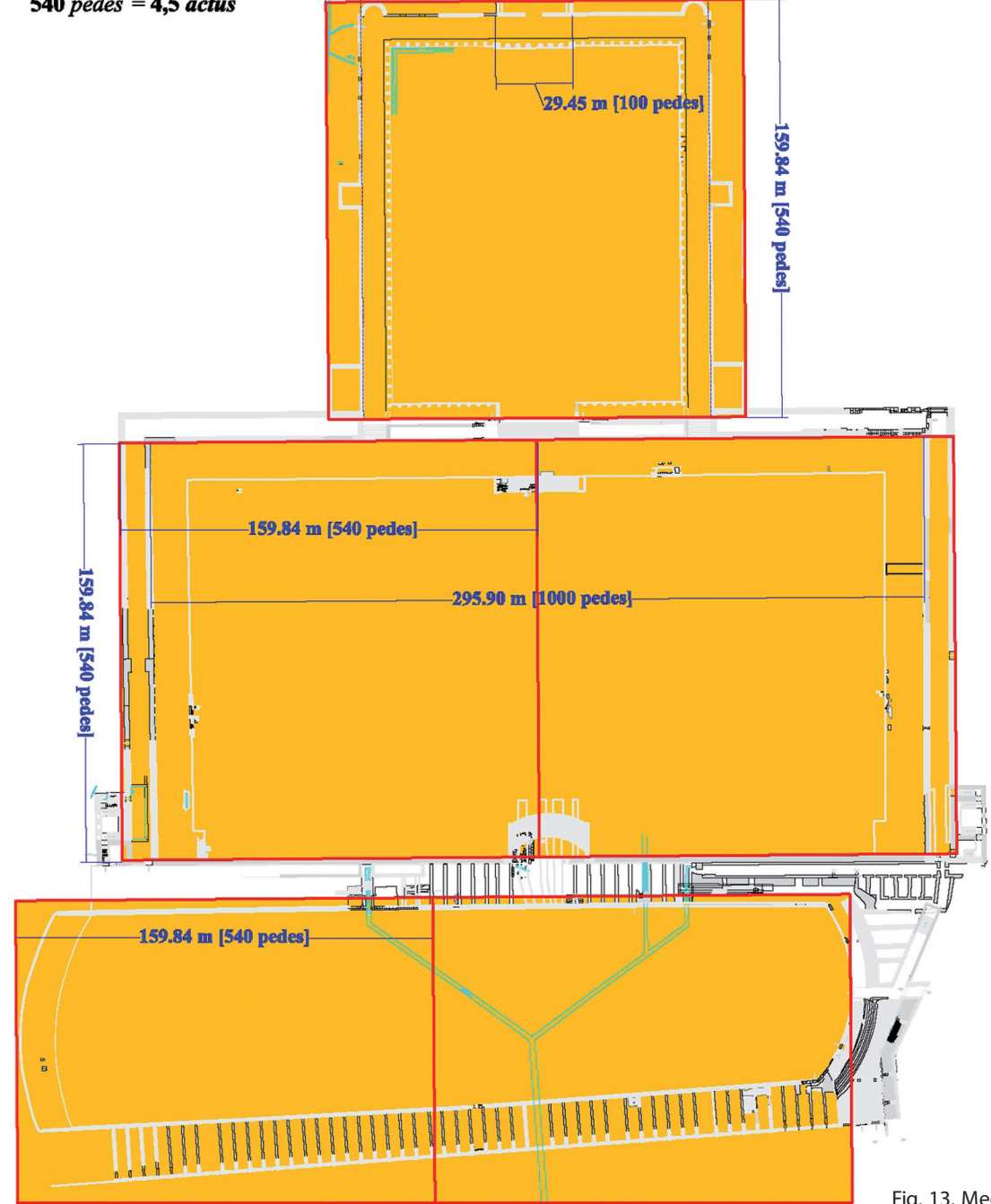

Fig. 13. Medidas y modulación del segundo proyecto constructivo

la relación entre los dos módulos se establezca en base sexagesimal no tiene por qué extrañar. Recordemos que en época clásica el 6 se consideraba uno de los números perfectos $(\mathrm{Vi}, \mathrm{III}, 1, \mathrm{v})^{42}$. De la misma manera que es normal en el mundo romano que las subdivisiones numéricas y métricas se establezcan en base sexagesimal. Así el codo se dividía en 6 palmos y el pie es $1 / 6$ de la altura de un hombre ${ }^{43}$, así como el actus son 120 (6x20) pies. Tampoco hay que olvidar que el pes viene

\footnotetext{
${ }^{42} \mathrm{La}$ "perfección" del numero 6 viene dada por ser el resultado de la suma de sus divisores. 6 sólo se puede dividir por 1,2 y 3 . Y la suma de estos tres números da 6. Esta propiedad la encontramos también en el número 28 (sus divisores son 1, $2,4,7,14$, y su suma da 28) que está considerado como el segundo número perfecto.

${ }^{43}$ De lo que se deduce que la altura teórica de un hombre se consideraba que era de 1,78 m., siempre según Vitrubio.
}

subdivido siguiendo un sistema doble sexagesimal-duodecimal ${ }^{44}$.

Volviendo al análisis del segundo proyecto, se puede documentar que la medida de 90 pedes (o su mitad de 45 pedes) se halla omnipresente. Si se dibuja una retícula con este módulo nos aparecen superpuestos o justificados la mayor parte de los elementos internos: los muros laterales de la plaza de la terraza superior, las aulas laterales, el interior de la sala axial y, curiosamente, el muro lateral del

\footnotetext{
${ }^{44}$ Las fracciones del pes se establecen en dos sistemas, el duodecimal (scripulum, sicilius, uncia, sextans, quadrans, triens, quincunx, semipes, septunx, bes, dodrans, dextans, y demunx o deunx) i el sexagesimal (scripulum, sicilius, digitus, sexuncia, palmus, semipes i palmus maior). En cambio, los múltiplos se establecen en un único sistema; palmipes, cubitus (o sexipedalis), dupondius (o bipedalis), gradus (o pes sextertius), passus, pertica (o decempeda), centum pedes (o viginti passus), actus, stadium, miliarium.
} 


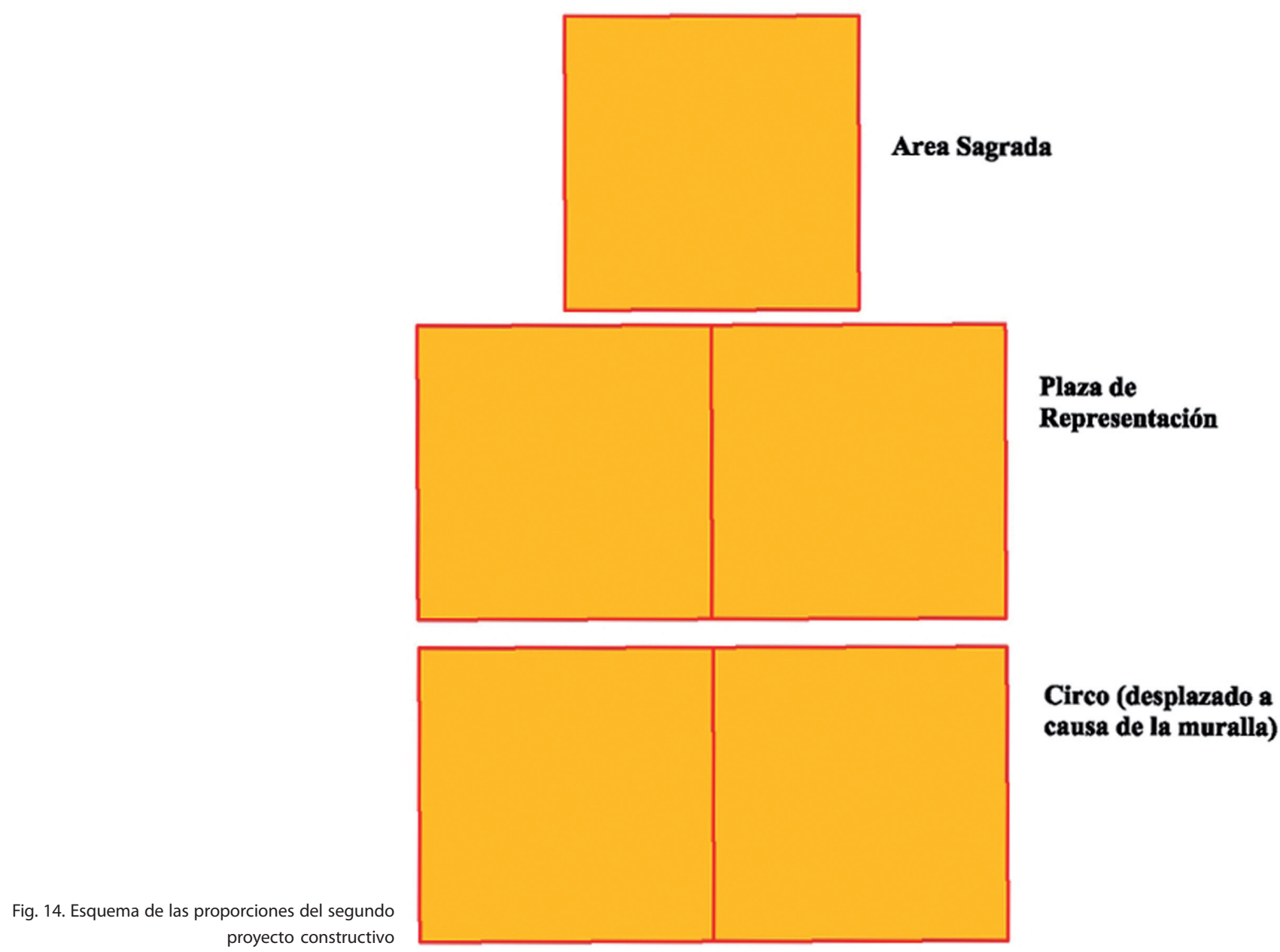

COAC (Macias et alii 2007, ficha 27), aunque este se haya datado en época tardía (Aquilué 1993) ${ }^{45}$, las dos «torres de acceso» a la terraza superior (Macias et alii 2007, fichas 64 y 67), la cisterna sita bajo la calle Sta. Anna (Macias et alii 2007, ficha 134), etc.

De forma paralela e independiente a nuestro trabajo, el equipo de excavaciones de la Catedral de Tarragona definieron la sección del porticado del temenos de la plaza superior, (Macias et alii 2007b, 779-780), el cual dió una modulación idéntica a la que nosotros proponemos (módulo cuadrado de 90 pedes), conclusión que confirmaría y avalaría nuestra propuesta (Fig. 16). En caso contrario, indicaría que hemos cometido el mismo tipo de error.

\section{CONCLUSIONES}

El monumento, la obra construida, es la consecuencia final de un proceso largo y complejo durante el cual la materia-

\footnotetext{
${ }^{45}$ Este muro tardo-antiguo está fosilizando la alineación de un posible pórtico. De hecho estaría cerrando un espacio que en época alto imperial ya estaba perfectamente delimitado.
}

lización de una idea predeterminada va evolucionando de forma significativa. El resultado visible es fruto de una evolución constante que nace desde el mismo momento en que alguien verbaliza la intención de construir. Y que continúa incluso después de su abandono, colapso u ocultamiento. Por esta razón, no es posible entender un elemento arquitectónico arqueológico si no se entienden sus procesos constructivos (quién, por qué, cómo y cuándo) y su evolución posterior.

El gran complejo monumental de la Part Alta de Tarragona, el conocido como Concilum Provinciale Hispania Citerioris, ha sido históricamente estudiado solo desde las perspectivas estilísticas y cronológicas, pero nunca desde las proyectuales o constructivas. Considerando tanto la gran complejidad del monumento así como sus dimensiones o el hecho de encontrase "oculto» debajo de la ciudad actual, es imposible entender su auténtica naturaleza sin entender los motores de su génesis y los diversos procesos constructivos a que se vio sometido.

Ignorar el tempo constructivo, el volumen del movimiento de tierras, la cantidad de mano de obra implicada, 


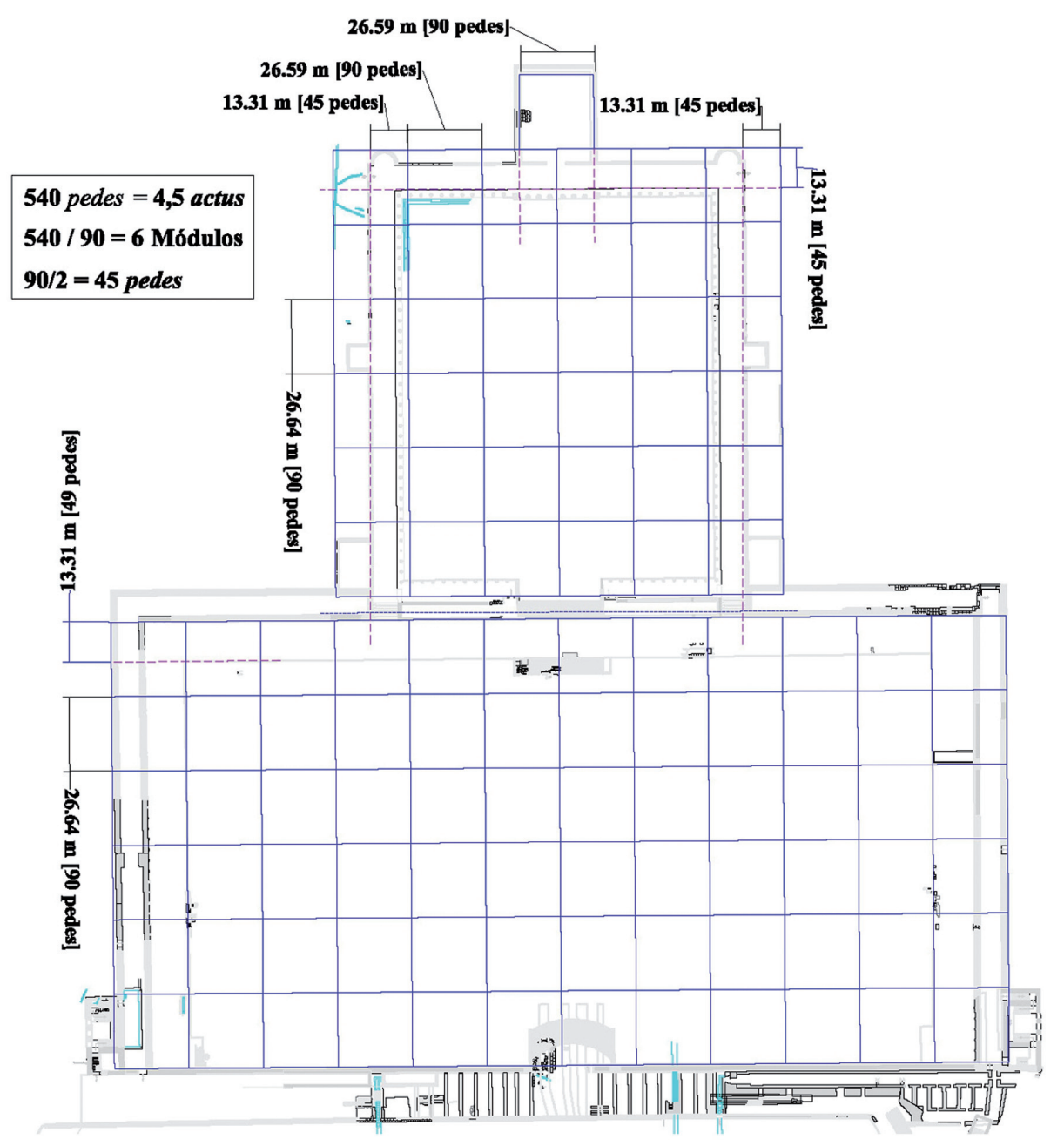

Fig. 15. Modulación interna de la segunda fase el cálculo del movimiento del flujo humano, la complejidad y extensión de las soluciones de ingeniería y de logística (muros de terraplén, drenaje, organización del trabajo, etc.) es, a nuestro parecer, un error que limita enormemente la perspectiva de estudio $y$, ante todo, la comprensión de este monumento.

Estas ausencias explican muchas de las incongruencias que aparecen implícitas en las afirmaciones de muchos estudios, tales como dar por sentado que parte del complejo funciona prácticamente desde inicios de época flávia, siendo todo una iniciativa de época de Domiciano. Nunca nadie, que nosotros sepamos, ha planteado la paradoja de cómo en un periodo tan breve de tiempo se pudieron realizar tamaños trabajos ni ha intentado cuantificar y valorar la extensión de tierra removida y excavada. Tampoco nadie ha reflexionado cuánto tiempo se necesita para construir las diversas edificaciones. Todo ello ha sido la razón principal de la enorme dificultad de entender la gran complejidad de todo el monumento, generando un conocimiento insuficiente y falseado de la realidad.
El Concilum Provinciale Hispania Citerioris nace como un concepto en una época determinada, porque hay una intención de materializarlo de una manera concreta. Pero como toda buena intención, la realidad existente, el tiempo pasado, los cambios de opinión hacen que el resultado final poco o nada se parezca a la idea original. No obstante, en ese resultado se recogen todas esas intenciones, dificultades y cambios de opinión que ha sufrido.

El análisis geométrico de los restos conocidos ha aportado nuevos datos que ayudan a confirmar su existencia y a comenzar a definir un primer proyecto constructivo que quedó, en un grado u otro, inacabado, y al cual se sobrepuso otro que, probablemente ${ }^{46}$, sí fue finalizado.

Se sabe además que el año $15 \mathrm{~d}$ C. se pidió autorización para la construcción de un templo dedicado a Augus-

\footnotetext{
${ }^{46}$ Probablemente, ya que hay elementos que permiten abrir la discusión sobre este tema. El discurso sobre cómo explicar la aparente ausencia de columnas en el podio de la plaza de representación permite plantear, como hipótesis de trabajo, la posibilidad de una no finalización de este segundo proyecto (Remolà y Pociña 1999).
} 


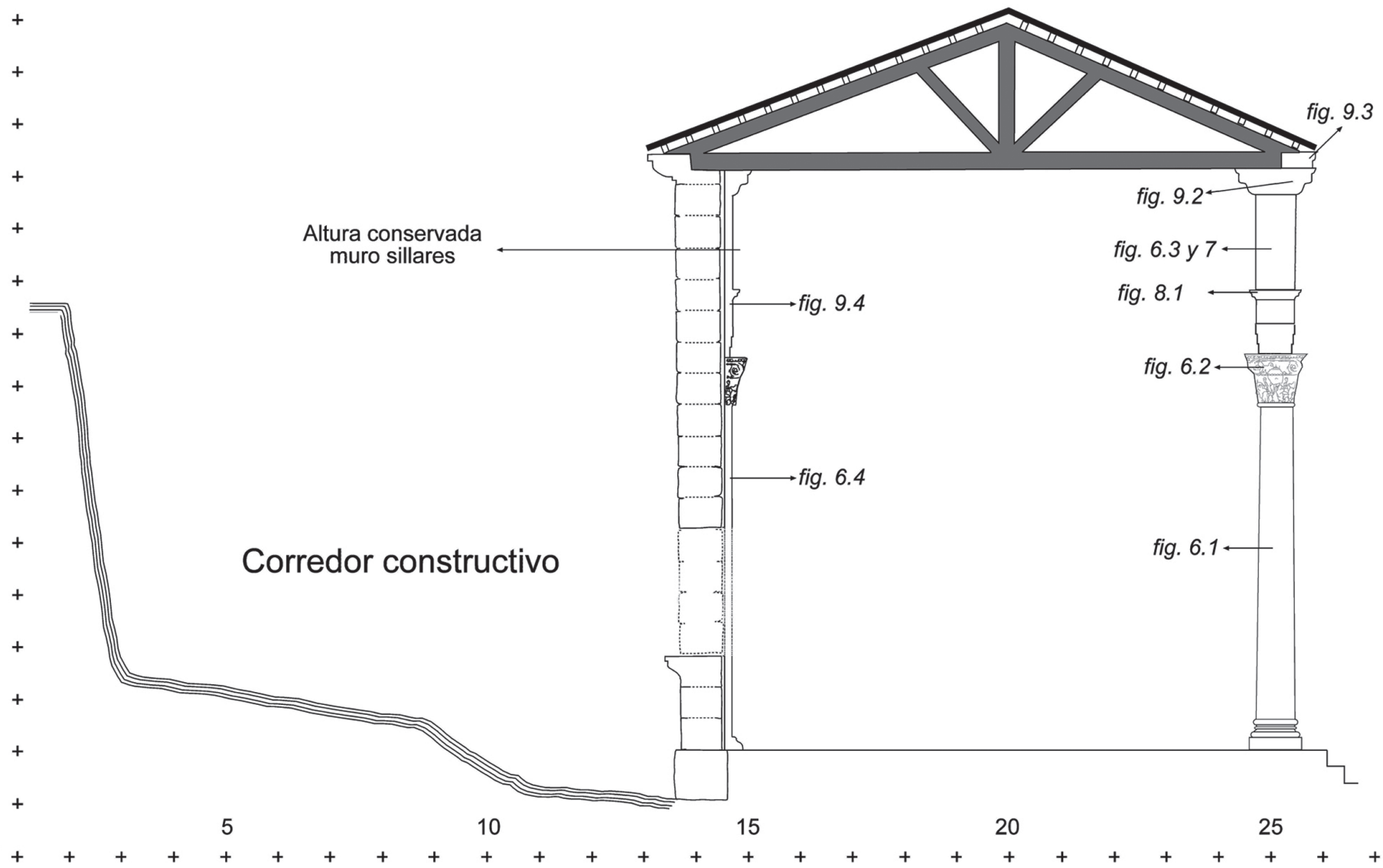

Fig. 16. Sección del porticado de la terraza superior según Muñoz et alii

to, de la misma manera que la monumentalización de la Part Alta se finaliza en época flavia avanzada. Estos dos hechos, aunque separados por un periodo de más de 80 años, seguramente presentan una fuerte relación de causalidad $y$, a nuestro parecer, no se debe desligar uno del otro ${ }^{47}$.

La existencia de dos proyectos, o como entendemos nosotros, el cambio radical del proyecto original, las circunstancias históricas y la propia magnitud de la obra explicarían perfectamente el dilatado tiempo existente entre la proyección y la realización ${ }^{48}$.

Por lo que respecta al patrocinio, es decir quien promovió y financió todo el proyecto, aún hay mucho por dis-

\footnotetext{
${ }^{47}$ Hecho ya apuntado por Aquilué $(1983,186)$ y posteriormente puesto en duda por Mar $(1993,111)$.

${ }^{48}$ Para ilustrar las dinámicas constructivas de la época y de los condicionantes sociales y políticos existentes, ver el proceso constructivo del Foro de Cesar, que incluye la Curia Iulia (Morselli y Torrorici 1989). Comienza a construirse en el 54 a.C. (Cic., Ad Att. 4, 16, 18) y se inaugura oficialmente el 26 de septiembre del 46 a.C. (8 años más tarde), con la obra aun no finalizada (Plin., Nat. Hist. XXXV, 155-156). Casi con toda seguridad, los trabajos se interrumpen con el asesinato de César en el 48 a.C. (los conjurados no pueden reunirse en la Curia que aun está en construcción, Cass.Dio. XLIV, 17, 8). A partir del 42 a.C., se reanudan los trabajos, culminándose en el 29 a.C., cuando Augusto inaugura la nueva Curia (Cass.Dio. LI, 22, 1). En total transcurren 25 años.
}

cutir. Aunque la iniciativa inicial fue provincial, hay pocas dudas de la implicación imperial en el proyecto. Ahora, el grado de esta implicación y si esta estuvo siempre presente a lo largo de todo el proceso es un aspecto a determinar.

Con los datos actuales se podría plantear el siguiente hilo conductor. En el año 15 d.C., justo al inicio del reinado de Tiberio, una embajada de la Tarraconense pide permiso para la construcción de un templo dedicado a Augusto (Tácito, Ann I, 78), y todo hace pensar que este fue concedido. De hecho, Tarraco destacará por ser la primera ciudad de Occidente en dedicar un templo a Augusto (Grosse 1959, 4), siendo un modelo a seguir para las otras capitales provinciales. No deja de ser significativa la coincidencia temporal con la oficialización de Tarraco como sede del Concilium Provinciae Hispaniae Citerioris (Alföldy $1991,59)^{49}$. Esto implicaría la necesidad, y la voluntad, de la construcción de un conjunto monumental que pretenda cubrir las necesidades administrativas que comporta la capitalidad provincial y las representativas vinculadas al nuevo culto imperial. Este último aspecto, el inicio del culto

\footnotetext{
${ }^{49}$ Coincidencia ya apuntada por Rovira (1993, 204).
} 
imperial, junto con la magnitud desproporcionada del proyecto (representa casi una cuarta parte del espacio intramuros de Tarraco) hacen suponer, a priori, un patrocinio imperial, el cual se hará más evidente con la grandiosidad del aparato decorativo marmóreo de época flavia y con las evidentes semejanzas con monumentos semejantes de promoción imperial en la misma capital del imperio.

Es posible que el proyecto se redactara ya en tiempo de Tiberio y que bajo este reinado se iniciaran, como mínimo, los trabajos previos. Su retirada a Capri en el año 26 (Svetonio se lamenta de la desidia del emperador en la administración de las provincias hispánicas) y el reinado de Calígula (con actitudes más bien contradictorias con los intereses de la Tarraconense (Grosse 1959, 9) debieron crear un ambiente poco propicio a la realización y continuación de grandes proyectos arquitectónicos y se podría suponer una parada o caída significativa del ritmo de los trabajos. Lo que sí está claro, es que parte significativa de la obra ya está realizada o en proceso de construcción, tal y como relevarían las marcas de cantero de época de Calígula en el gran muro de sillares del Pretorio.

Esto podría haber cambiado con la llegada de Claudio y, sobre todo, de Nerón. No en vano, son de este periodo los primeros niveles constructivos que se pueden datar ceramológicamente. Dada la magnitud del desmonte y del terraplén y la naturaleza propia del terreno (predominio del «fetxe de gat», roca calcárea extremadamente dura $)^{50}$, estos trabajos preparatorios habrían necesitado forzosamente varios años, por no decir lustros, para su conclusión $^{51}$ (Fig. 17 y 18).

Es de destacar que en época de Nerón, Galba, quien después se convertirá en el primer emperador de la dinastía flavia, fue denominado Legatus Augusti pro praetore de la Tarraconense (Grosse 1959, 14), y no sería extraño que hubiese tenido algún tipo de responsabilidad de las obras en curso.

\footnotetext{
${ }^{50}$ Como ejemplo y a nivel ilustrativo. A inicios del actual siglo se procedió a la construcción del desafortunado parque de Jaume I, en plena Part Alta (Macias et alii 2007, ficha 7). Para poder rebajar 12 metros una superficie de unos $2.500 \mathrm{~m}^{2}$ (unos $30.900 \mathrm{~m}^{3}$ ) se necesitaron 18 meses de trabajo con maquinaria pesada $y$ explosivos (trabajando 6 días a la semana, 10 horas al día). Si extrapolamos este dato a la totalidad de la zona rebajada durante la construcción del CPHC con la tecnología de la época, nos daremos cuenta de las dimensiones del esfuerzo y tiempo requerido.

${ }^{51}$ Aun no se ha contabilizado, aunque sea aproximadamente, el volumen real de todo este movimiento de tierras, como tampoco se ha hecho una estimación del tiempo que se podría haber necesitado para su realización. Una estimación somera nos indicaría que se movieron en torno a los $500.000 \mathrm{~m}^{3}$ de tierras y la práctica nos indica que un promedio de excavación y extracción de $1 \mathrm{~m}^{3}$ por grupo de $3 \mathrm{o}$ 4 personas al día en terreno rocoso es un cálculo posible. Así, 3 o 4.000 obreros tardarían más de 10 años en completar este desmonte. Pero repetimos, este es un cálculo aproximativo, aunque nos indica de qué magnitudes estamos hablando.
}

Todo parece indicar que este proyecto no llegó nunca a finalizarse, sin que podamos saber hasta qué punto se completó. En la terraza superior, la construcción de la zanja detectada en el claustro de la catedral (Macias et alii 2007, 23) implica que el rebaje de esta zona debería estar ya finalizada, pero también que no se construyó la estructura a la que servía. No sabemos nada seguro del templo, aunque las últimas publicaciones lo dan indiscutiblemente por una obra julio-claudia (Pensabene y Mar 2004 y Macias et alii en prensa). La existencia de monedas tiberianas que representan el templo (Benages 1994, 30) ${ }^{52}$ y el hecho de que a partir del año 70 ya hay noticias sobre celebraciones religiosas hacen suponer que debería de estar acabado antes del cambio de dinastía. A ello se debe añadir que la última propuesta reconstructiva del templo (Pensabene y Mar 2009) le otorga la misma proporción que la propuesta reconstructiva del primer proyecto, lo que reforzaría la idea de su contemporaneidad. La existencia de numerosos restos de decoración arquitectónica de época julio-claudia ${ }^{53}$ indicaría que parte de las obras ya estarían lo suficientemente adelantadas como para poder soportar elementos decorativos.

En el lugar de la posterior la plaza de representación, se puede asegurar que el muro de contención, definido por el muro de sillares con cimentación de caementicium, se construye ya en este momento y todo parece indicar que estaría totalmente acabado. A nivel hipotético se podría considerar que parte de las obras preparatorias de la construcción del muro occidental ya estarían finalizadas, no sabemos si sólo el rebaje de la colina o si ya se había empezado a construir la obra de fábrica. Esto podría explicar la divergencia de alineación de este sector documentado en la construcción flavia y sería coherente con los datos extraídos durante la excavación del C/ del Comte 12/ 14 (Macias et alii 2007, ficha 168$)^{54}$ y los niveles más antiguos del claustro de la catedral (Rüger 1968).

Ignoramos qué sucede en la zona del circo. $\mathrm{Ni}$ tan sólo podemos especular sobre si el proyecto preveía, o no, la

\footnotetext{
${ }^{52}$ Hay dos acuñaciones con la representación del templo, una de sestercios, en la que el templo se eleva sobre un podio, y otra en dupondios, en la que aparece con una escalinata central. El autor considera que esta divergencia se debe a que retratan la situación del templo en dos momentos constructivos diferentes (Benages 1994, 30).

53 Sobre el tema, ver Mar (1993), Pensabene (1993) y Koppel y Rodà (1996). Como último estudio crítico publicado sobre el tema, ver Macias et alii (2007b). ${ }^{54}$ En esta excavación se documentaron los niveles fundacionales del muro del podio que delimita la plaza de representación. Los materiales recuperados se podrían situar perfectamente a finales de época julio-claudia, aunque también serían coherentes con una datación domiciana inicial. En su publicación, aplicando un razonamiento circular, se dieron a estos niveles constructivos una datación flavia con el argumento que la construcción del muro tenía que ser, necesariamente, de época flavia (Remolà y Pociña 1999).
} 


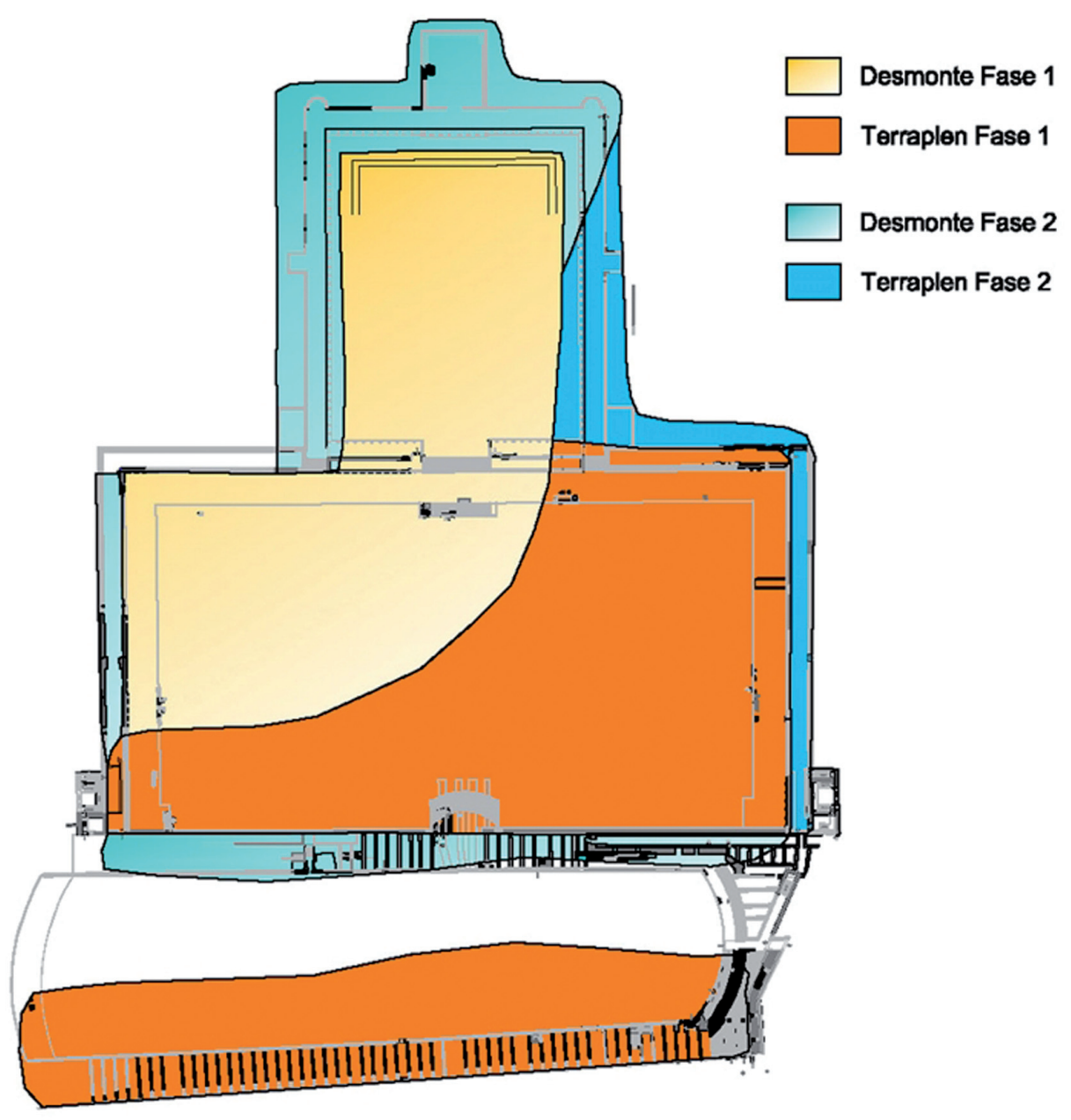

construcción de un circo o un edificio similar. Lo que sí se puede asegurar es que, en ese momento, se están realizando importantes trabajos de nivelación y regularización del terreno y que, muy probablemente, se utilizaría como base para la infraestructura necesaria de una obra de tal magnitud. La presencia de determinados elementos pre-flavios en la zona de la «volta llarga» (Vinci 2009) da pie a pensar en la voluntad de construir alguna estructura, de la cual, por el momento, desconocemos prácticamente todo.

Este proyecto inicial viene radicalmente modificado en un momento que deberemos hacer coincidir con la subida al poder de los flavios. Los cambios que implica el segundo proyecto son de tal magnitud que tiene que haber un poderoso motivo que los justifique, y este sólo puede ser el cambio de dinastía que comportaría, entre otras muchas cosas, la intención de consolidar la imagen del poder imperial. Son lo suficientemente conocidas las actividades del primer emperador flavio en este sentido: construcción del Forum Pacis en Roma (71-75 d.C.; Coarelli 1994, 145), construcción del anfiteatro flavio (72-
80 d.C.; Coarelli 1994, 188), creación del cargo de flamen provinciae hispaniae citerioris cerca del año $70 \mathrm{~d}$.C. (Alföldy 1991, 46) y la concesión del derecho latino a las provincias hispánicas el año 74 (Grosse 1959, 31). Dentro de este marco, y sobre todo con las dos últimas acciones, es coherente la intención imperial de dotar a la capital provincial de la Tarraconense de un gran complejo monumental que recordaría perennemente y reforzaría la idea del poder imperial.

La llegada al poder de Vespasiano se da en una fase avanzada de construcción de un gran complejo monumental. Este es modificado y engrandecido a fin de ajustarlo a un nuevo concepto de monumentalidad y de representación simbólica arquitectónica. No en vano, lo que en origen se había definido como un espacio estructurado rectangularmente se convierte ahora en un espacio pensado y estructurado en base a un cuadrado ${ }^{55}$.

\footnotetext{
55 Este cambio no es ninguna banalidad, pues implica una alteración en la concepción y en la percepción simbólica del espacio.
} 

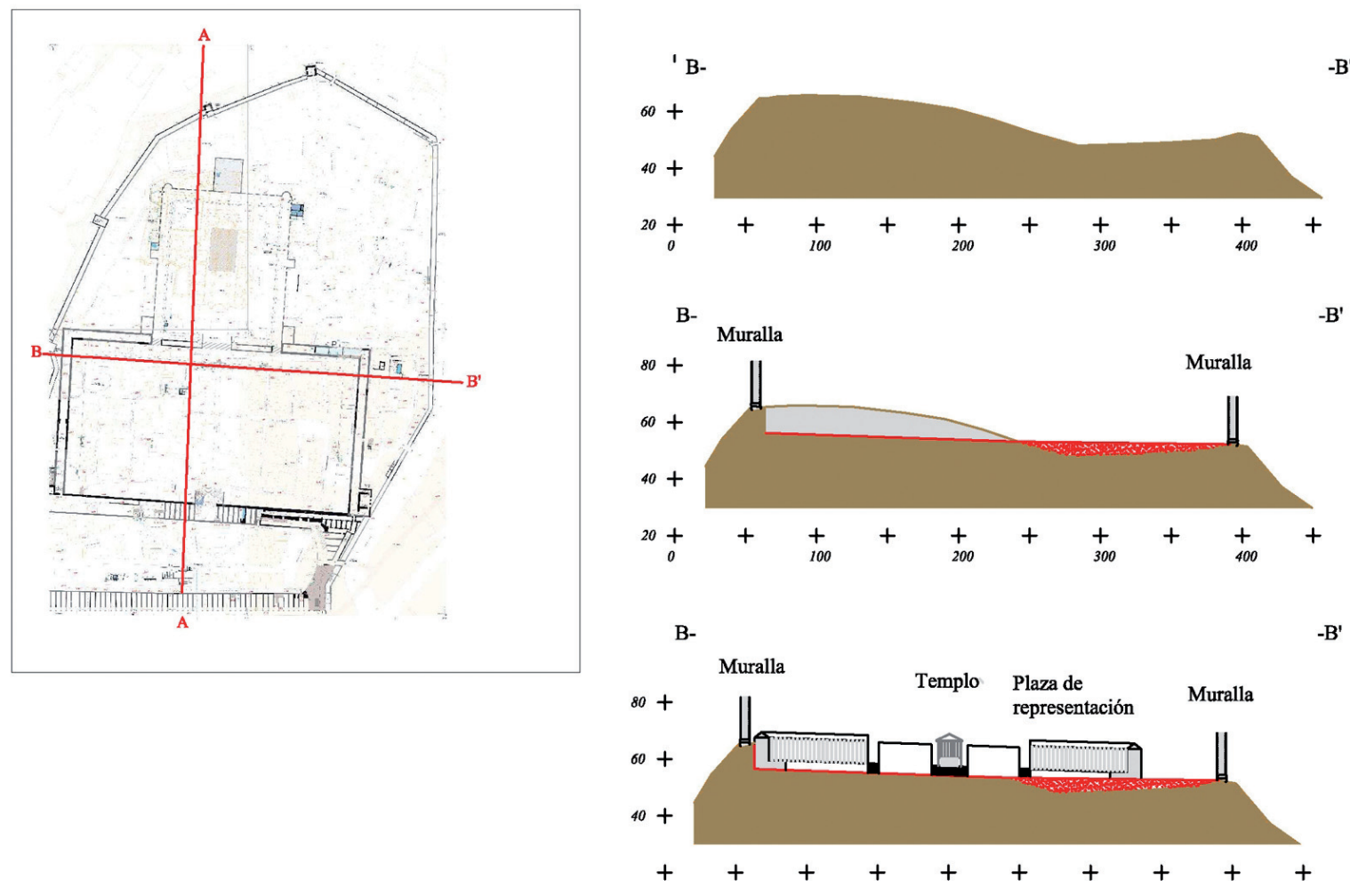

A-

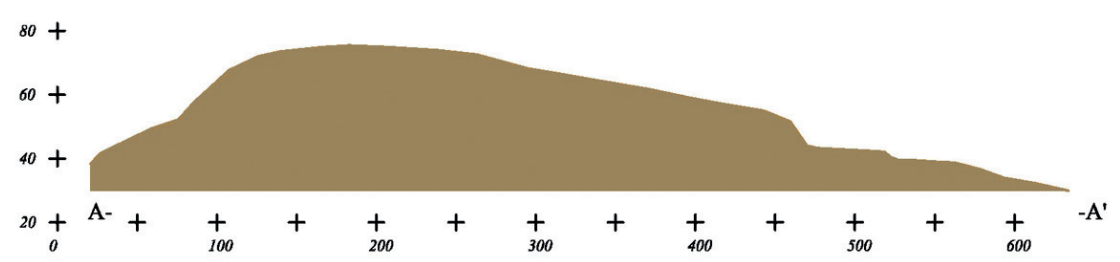

Muralla

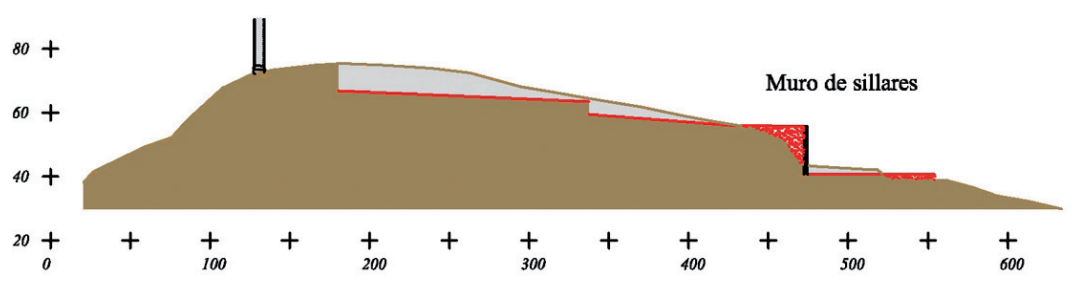

A-

$-\mathbf{A}^{\prime}$

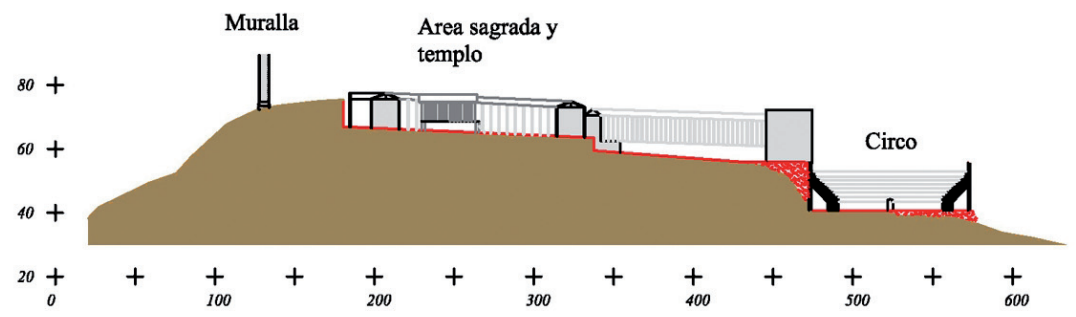

Fig. 18. Secciones evolutivas de las modificaciones de la colina de la Part Alta de Tarragona 
Se desmonta parte de las construcciones ya realizadas, se amplía la terraza superior hasta hacerla cuadrada, se aprovecha el muro de contención de la terraza mediana pero, al mismo tiempo, se eleva su nivel de circulación (al menos en la zona de la torre del Pretori) y se define definitivamente la área del circo. Probablemente se aprovecha el rebaje del lado occidental de la plaza de representación. Como ya hemos apuntado anteriormente, el hecho de que tanto la instauración del cargo de flamen provincial como el inicio de las actividades cultuales se puedan situar en torno el año 70 (Alföldy 1991, 46) nos hace creer que el templo y la área sagrada ya estaba en un proceso constructivo muy adelantado cuando se produce el cambio dinástico. Es muy difícil creer que en dos o tres años se pudiera adecuar toda el área y construir el templo.

Lo último en finalizarse seria el circo en época de Domiciano (Dupre et alii 1988), de modo coherente con la organización horizontal del programa constructivo. La existencia del circo, finalizado o en construcción, previa a la finalización de las obras de las dos terrazas superiores hubiese acarreado importantes problemas logísticos para el libre movimiento de materiales y personal ${ }^{56}$.

Este segundo proyecto se caracterizaría por el uso de un módulo cuadrado de 4,5 actus subdividido en módulos internos de 90 pies, que da como resultado una estructura geométrica muy simple y ordenada que permitiría definir rápidamente la mayor parte de todos sus elementos internos.

La importancia real y el significado del cambio de proporciones y módulos entre el primero y el segundo proyecto se nos escapa. Sería un interesante tema de estudio que pondría en relación el cambio en la percepción del espacio con el cambio dinástico. Lo que si parece evidente es que la concepción, la génesis y la ejecución de la monumentalización de la Part Alta de Tarragona es un proceso complejo con una dinámica interna que tiene que ser, forzosamente, entendida. Hay una intención clara en la monumentalización de la acrópolis tarraconense y tendría que ser evidente que una de las herramientas para conseguir el objetivo buscado es la forma. Un cambio de forma solo puede darse por otro

\footnotetext{
${ }^{56}$ Se podría pensar en un plan de trabajo que implicase un orden constructivo en horizontal. Significativamente es en la terraza superior donde se documentan los indicios constructivos más antiguos, siendo los más modernos, los que darían por finalizada toda la obra, los situados en el circo. La praxis constructiva, los tiempos y la organización del trabajo hacen lógico pensar que sea el circo el último elemento a construir. Hasta que las dos terrazas superiores no estuvieran finalizadas, sería conveniente tener libre el espacio del circo, tanto para facilitar el movimiento y el acceso como para poder disponer de un amplio espacio dónde colocar toda la infraestructura de la obra.
}

en la concepción del lenguaje o del mensaje que se quiere transmitir.

Nos encontramos no con un gran proyecto, sino con dos, que implican un periodo constructivo temporal de unos 70-75 años y que afectan a dos dinastías. Comportan dos concepciones espaciales diferentes que además están superpuestas físicamente estableciéndose un dialogo casuístico entre ellos. No creemos estar delante de un caso único o peculiar, sino ante un ejemplo más de un fenómeno posiblemente amplio y profundo. No se pueden negar las amplias similitudes con la evolución de la casa de Augusto (Carandini 2008), embrión del palacio imperial del Palatino, que presenta, aparentemente una estructura formal y una evolución cronológica perfectamente paralelizable con el caso de Tarraco.

Dejamos para otros trabajos el confirmar y acotar, si se da el caso, la generalización de estos procesos y las implicaciones (a nivel de semántica de la arquitectura y del lenguaje del poder) que puede implicar.

\section{Bibliografía}

AA.VV. (1999). Excavacions arqueològiques a la Plaça de la Font. Tàrraco 99. Arqueologia d'una capital provincial romana, 61-71.

Alföldy, G. (1975). Die Römischen Inschriften von Tarraco. Berlín.

Alföldy, G. (1991). Tarraco. Tarragona: Fòrum, temes d'història i arqueologia tarragonines-8.

Aquilué, X. (1983). Aportacions al coneixement de la terrassa superior de Tàrraco en l'època alt imperial. Butlletí Arqueològic , 178-194.

Aquilué, X. (1993). La seu del Col.legi d'Arquitectes. Una intervenció arqueològica en el centre històric de Tarragona. Tarragona: COAC.

Aquilue, X., \& Dupré, X. (1986). Reflexions entorn de Tarraco en època tardorepublicana. Tarragona: Fòrum, temes d'història i arqueologia tarragonines - 1 .

Arias, L. (2008). Geometría y proporción en la arquitectura prerrománica asturiana. Madrid: Anejos de Archivo Español de Arqueología XLIX.

Benages, J. (1994). Les monedes de Tarragona. Tarragona: Societat Catalana d'Estudis Numismàtics.

Bermúdez, A. (1992). Estructuras del Foro Provincial documentadas en Escrivanies Velles, 13. Butlletí Arqueològic (13), 83-109.

Caveing, M. (1998). L'irrationalité dans les mathématiques grecques jusqu’à Euclide. Villeneuve d'Ascq: Presses universtaires du Septrion.

Coarelli, F. (1994). Roma. Roma: Guide Archeologiche Mondadori.

Corbusier, L. (1923). Vers une architecture. Paris.

Cortés, R., \& Grabriel, R. (1981). Elements dels conjunts arquitectònics de les terrasses mitjana i superior de Tarraco. Butlletí Arqueològic (3), 122-126.

Dupré, X., \& Subías, E. (1993). Els precedents de l’anomenat Pretori de Tarragona. (E. U. XXIX, Ed.) Homenatge a Miquel Tarradell, 603-609.

Dupre, X., Massó, J., Palanques, L., \& Verduchi, P. (1988). ,El Circ romà de Tarragona, I. Les Voltes de Sant Ermenegild. Barcelona: Excavacions Arqueològiques a Catalunya num. 8.

Esposito, F., \& Michetti, A. (1996). Il Pantheon: teoria e tecnica della commodulatio. Disegnare, Rivista semestrale del Dipartimento di Rappresentazione e Rilievo, Università degli Studi di Roma «La Sapienza» (13), 69-80.

Gebellí, P. (1999). Noves aportacions al coneixement històric de la part alta de Tarragona. La intervenció arqueològica a la Plaça de la Font de Tarragona. Butlletí Arqueològic (19-20), 153-196.

Giuliani, C. F. (1983). Archeologia. Documentazione grafica. Roma: de Luca editore.

Giuliani, C. F. (2006). L'edilizia nell'antichità. Roma: Ed. Carocci.

Grosse, R. (1959). Las fuentes desde César hasta el siglo V d.C. Barcelona: Fontes Hispaniae Antiquae VIII. 
Hauschild, T. (1983). Arquitectura romana de Tarragona. Tarragona.

Hultsch, F. (1882). Griechische und Römische metrologie. reimpresión hecha por la Akademische Druck-u. Verlagsanstalt, Graz, Austria, 1971.

Ivain, G. (1958). Formulario para un nuevo urbanismo. París: International Situationniste.

Koppel, E., \& Rodà, I. (1996). Escultura decorativa de la zona nororiental del Conventus Tarraconensis. Actas de la II reunión sobre escultura romana en Hispania, 135-181.

Livio, M. (2006). La proporción aurea. Barcelona: Ariel.

López, J. y Piñol, L. (2008). Terracotes arquitectòniques romanes. Les troballes de la Plaça de la Font (Tarragona). Tarragona: ICAC.

López, J. y Puche, J. (en prensa). Metrología y proporciones en las basílicas paleocristianas de Tárraco: la basílica septentrional del santuario suburbano de San Fructuoso y la basílica del anfiteatro. XV Congreso Internacional de arqueologia cristiana. Toledo 2008.

Macias, J. (1999). Lúrbanisme de Tarraco a partir de les excavacions de l'entorn del Fòrum de la ciutat. Tarraco 99. Arqueologia d'una capital provincial romana. , 83-106.

Macias, J., Fiz, I., Piñol, L., Miró, M. y Guitart, J. (2007). Planimetria arqueologica de Tarraco. Tarragona: ICAC.

Macias, J., Menchón, J., Muñoz, A. y Teixell, I. (2007b). Excavaciones en la catedral de Tarragona y su entorno: Avances y retrocesos en la investigación sobre el Culto Imperial. Culto Imperial: Politica y poder. Congreso internacional $2006,765-787$.

Macias, J., Muñoz, A., Teixell, I. y Menchón, J. (en prensa). La construcción del recinto de culto imperial de Tarraco. Tarraco: construcció d'una arquitectura d'una capital provincial romana". Homenage a Theodor Hauschild. 28-01-09 a 30-01-09.

Mar, R. (1993). El recinto de culto imperial de Tárraco y la arquitectura flavia. Els monuments provincials de Tarraco. Noves aportacions al seu coneixement. Documents d'arqueologia Clàssica 1 , 107-157.

Mar, R. y Pensabene, P. (2004). Dos frisos marmóreos en la acrópolis de Tarraco, el templo de Augusto y el complejo provincial de culto imperial. Simulacra Romae. Roma y las capitales provinciales del occidente europeo. Estudios arqueológicos.

Markowsky, G. (1992). Misconceptions about the Golden Ratio. Orono, Maine: College Mathematical Journal.

Martín, O. y Rovira, J. (2009). Arquitectura i urbanisme de la Part Alta de Tarraco en època Republicana $i$ Imperial. Tarragona: Tarraco Archaelogica . Reial Societat Arqueològica Tarraconense.

Mies van der Rohe, L. (1924). Arquitectura y modernidad. Ed. 1990 Barcelona: Paidos.

Morselli, C. y Torrorici, E. (1989). Curia, Forum Iulium, Forum Transitorium. Roma: Lavori e Studi di Archeologia. Soprintendenza Archeologica di Roma.

Muller, B. (1998). L'homme qui fabriquait les maquettes au proche-orient... Maquettes atchitecturales de l'Antiquité. Actes de Colloque de Strasbourg, 3-5 diciembre 1998, 331-356.

Pensabene, P. (1993). La decorazione architettonica dei monumenti provinciale di Tarraco. Els monuments provincials de Tarraco. Noves aportacions al seu coneixement. Documents d'arqueologia Clàssica 1, 33-105.
Pensabene, P. (2005). Nouvi ritrovamenti di fregi marmorei dall'acropoli di Tarraco e i complessi monumentali di culto imperiale. Théorie et pratique de l'architecture romaine. Études offertes à Pierre Gros (2004), 233-246.

Pensabene, P. y Mar, R. (2009). Arquitectura i organització d'obres al Fòrum Provincial deTarraco Conferencia dada a «Tarraco: construcció d'una arquitectura d'una capital provincial romana». Homenage a Theodor Hauschild 2801-09 a 30-01-09, Tarragona.

Pensabene, P. y Mar, R. (2004). Dos frisos marmóreos en la Acrópolis de Tarraco, el templo de Augusto y el complejo provincial de culto imperial. Simulacra Romae. Roma y las capitales provinciales del Occidente Europeo. Estudios Arqueológicos, 73-86.

Piñol, L. (2000). Voltes del Pretori (C/ Enrajolat i Casa dels Militars). Intervencions arqueològiques a Tarragona i entorn (1993-1999), 89-107.

Puche, J. (2006). Metrologia, modulació, proporcions i proposta d'alçats. En J. López, Les basíliques paleocristianes del suburbi occidental de Tarraco (págs. 126134). Tarragona: ICAC.

Puche, J., Macias, J. y Fiz, I. (2007). Projeccions urbanístiques. En Planimetria. Tarragona: ICAC.

Remolà, J. y Pociña, C. (1999). La plaza de representación de Tárraco: intervenciones arqueológicas en la plaza del Forum y la calle d'En Compte. Tàrraco 99. Arqueologia d'una capital provincial romana, 27-47.

Ruiz de Arbulo, J. (2002). El altar y el templo de Augusto en la colonia Tarraco. Estado de la cuestión. En Fora Hispaniae. Paisaje urban, arquitectura, programas decorativos y culto imperial en los foros de las ciudades hispanorromanas. Monografías del Museo Arqueológico de Múrcia, num. 3, 155-191

Rovira, J. (1993). Alguns aspectes per a la contextualització històrica del Fòrum Provincial de Tarraco. Els monuments provincials de Tàrraco. Noves aportacions al seu coneixement. Documents d'arqueologia clàssica 1, 195-229.

Rüger, C. (1968). Römische Keramik aus dem Krezgang der Kathedrale von Tarragona. Madrider Mitteilungen (9), 237-258.

Sánchez Real, J. (1969). Exploración arqueológica en el jardín d ela catedral de Tarragona. Madrider Mitteirlungen (10), 276-301.

Scholfield, P. (1971). The theory of proportion in Architectura. Cambridge: Syndics of the Cambrige University press.

Taylor, R. (2003). Roman Builders. A study in architectural process. Cambridge: Cambridge University press.

T’EDA. (1989). El Foro Provincial de Tarraco, un complejo arquitectónico de época flavia. Archivo Español de Arqueologia (62), 141-191.

Vázquez Queipo, V. (1859). Essai sur les systémes metriques et monetaires des anciens peuples depuis les premiers temps historiques jusqué a la fondu Kalifat d'Orient. Paris.

Vinci, S. (2009) Studio e contestualizzazione storico-archeologica della denominata Volta Llarga. Trabajo final del Master Interuniversitari en Arqueologia Clàssica de la URV-ICAC-UAB.

Wilson Jones, M. (2003). Principles of roman architecture. Londres: Yale University Press.

Recibido: 29 de junio de 2010 Aceptado: 2 de noviembre de 2010 